\title{
CanadianJournal of
}

HealthTechnologies

April 2021 Volume 1 Issue 4

CADTH Health Technology Review

Flash Glucose Monitoring Systems in Pediatric

Populations With Diabetes 
Authors: Calvin Young, Aleksandra Grobelna

ISSN: $2563-6596$

Disclaimer: The information in this document is intended to help Canadian health care decision-makers, health care professionals, health systems leaders, and policy-makers make well-informed decisions and thereby improve the quality of health care services. While patients and others may access this document, the document is made available for informational purposes only and no representations or warranties are made with respect to its fitness for any particular purpose. The information in this document should not be used as a substitute for professional medical advice or as a substitute for the application of clinical judgment in respect of the care of a particular patient or other professional judgment in any decision-making process. The Canadian Agency for Drugs and Technologies in Health (CADTH) does not endorse any information, drugs, therapies, treatments, products, processes, or services.

While care has been taken to ensure that the information prepared by CADTH in this document is accurate, complete, and up-to-date as at the applicable date the material was first published by CADTH, CADTH does not make any guarantees to that effect. CADTH does not guarantee and is not responsible for the quality, currency, propriety, accuracy, or reasonableness of any statements, information, or conclusions contained in any third-party materials used in preparing this document. The views and opinions of third parties published in this document do not necessarily state or reflect those of CADTH.

CADTH is not responsible for any errors, omissions, injury, loss, or damage arising from or relating to the use (or misuse) of any information, statements, or conclusions contained in or implied by the contents of this document or any of the source materials.

This document may contain links to third-party websites. CADTH does not have control over the content of such sites. Use of third-party sites is governed by the third-party website owners' own terms and conditions set out for such sites. CADTH does not make any guarantee with respect to any information contained on such third-party sites and CADTH is not responsible for any injury, loss, or damage suffered as a result of using such third-party sites. CADTH has no responsibility for the collection, use, and disclosure of personal information by third-party sites.

Subject to the aforementioned limitations, the views expressed herein are those of CADTH and do not necessarily represent the views of Canada's federal, provincial, or territorial governments or any third-party supplier of information.

This document is prepared and intended for use in the context of the Canadian health care system. The use of this document outside of Canada is done so at the user's own risk.

This disclaimer and any questions or matters of any nature arising from or relating to the content or use (or misuse) of this document will be governed by and interpreted in accordance with the laws of the Province of Ontario and the laws of Canada applicable therein, and all proceedings shall be subject to the exclusive jurisdiction of the courts of the Province of Ontario, Canada.

The copyright and other intellectual property rights in this document are owned by CADTH and its licensors. These rights are protected by the Canadian Copyright Act and other national and international laws and agreements. Users are permitted to make copies of this document for non-commercial purposes only, provided it is not modified when reproduced and appropriate credit is given to CADTH and its licensors.

About CADTH: CADTH is an independent, not-for-profit organization responsible for providing Canada's health care decision-makers with objective evidence to help make informed decisions about the optimal use of drugs, medical devices, diagnostics, and procedures in our health care system.

Funding: CADTH receives funding from Canada's federal, provincial, and territorial governments, with the exception of Quebec.

Questions or requests for information about this report can be directed to Requests@CADTH.ca 


\section{Table of Contents}

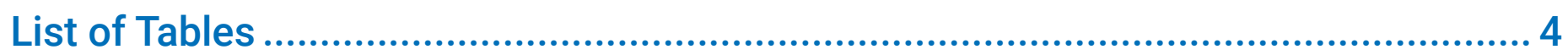

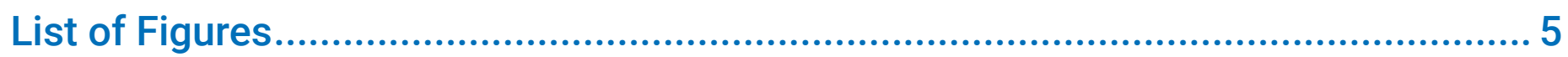

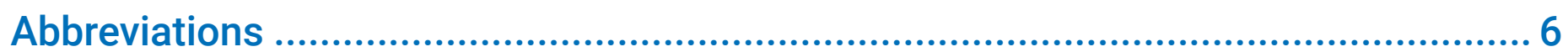

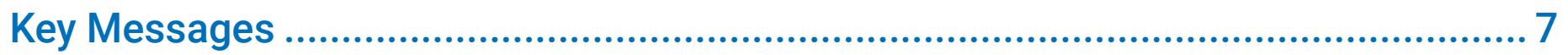

Context and Policy Issues ................................................................................ 7

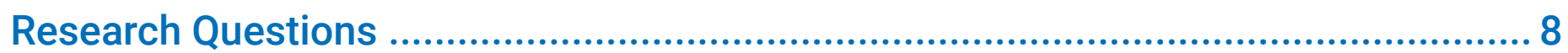

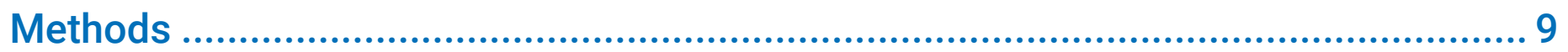

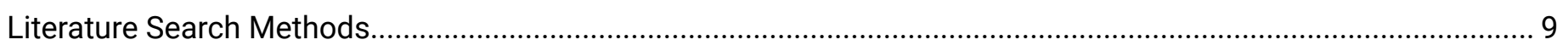

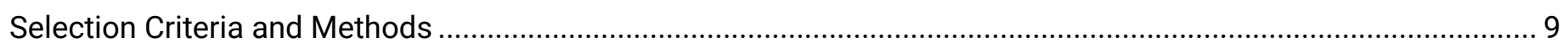

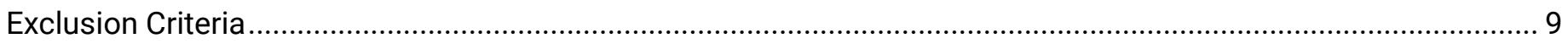

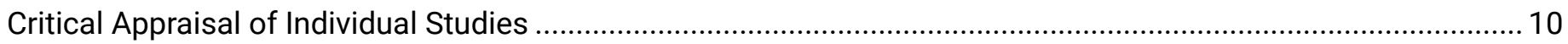

Summary of Evidence....................................................................................... 10

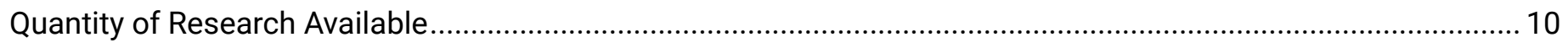

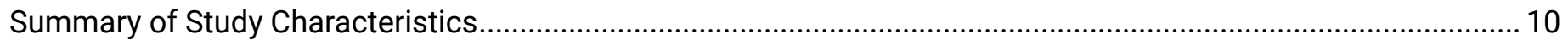

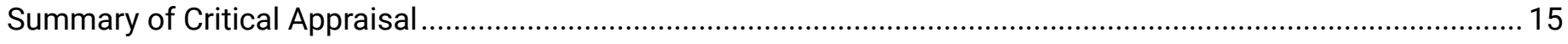

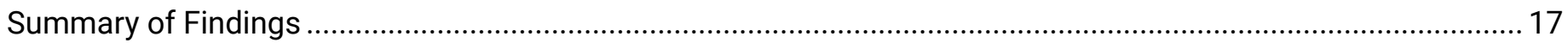

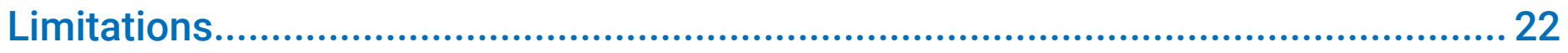

Conclusions and Implications for Decision- or Policy-Making ................................... 23

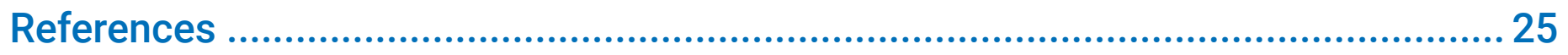

Appendix 1: Selection of Included Studies ............................................................... 27

Appendix 2: Characteristics of Included Publications ................................................. 28

Appendix 3: Critical Appraisal of Included Publications ............................................... 39

Appendix 4: Main Study Findings and Authors' Conclusions ..................................... 48

Appendix 5: References of Potential Interest .............................................................67 67 


\section{List of Tables}

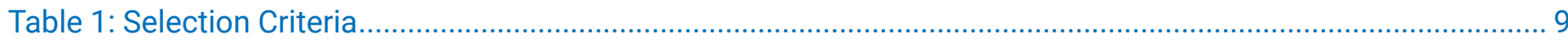

Table 2: Characteristics of Included Health Technology Assessments and Systematic Reviews ..........................28

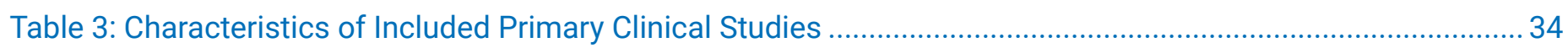

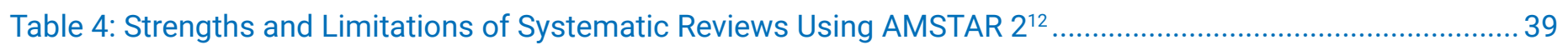

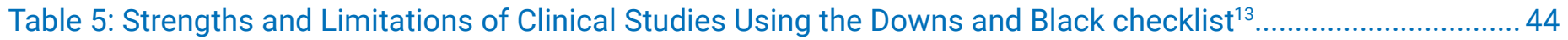




\section{List of Figures}

Figure 1: Selection of Included Studies. 


\section{Abbreviations}

AMSTAR 2 A MeaSurement Tool to Assess systematic Reviews 2

BMI body mass index

CGM continuous glucose monitoring

CI confidence interval

CIDS Confidence in Diabetes Self-Care

DQOLY Diabetes Quality of Life for Youth

DTSQ Diabetes Treatment Satisfaction Questionnaire

FGM flash glucose monitoring

HFS Hypoglycemia Fear Survey

IQR interquartile range

MDII multiple daily insulin injections

PedsQL Pediatric Quality of Life Inventory

RCT randomized controlled trial

SD standard deviation

SMBG self-monitoring blood glucose

T1-DDS 28-item T1-Diabetes Distress Scale

WHO-5 5-item World Health Organization Well-Being Index 


\section{Key Messages}

- Flash glucose monitoring (FGM) is a method of glucose testing where a sensor inserted into the skin continuously measures interstitial glucose levels. It can be used by people with diabetes to inform treatment decisions, such as insulin dosing, as an alternative or complement to blood glucose testing.

- Evidence of variable quality from 2 randomized controlled trials and 8 non-randomized studies, including those summarized within systematic reviews, suggests that FGM may improve quality of life, patient satisfaction, diabetes distress, self-efficacy, and frequency of glucose monitoring compared to self-monitoring blood glucose techniques in pediatric populations with type 1 diabetes. Findings related to other outcomes, such as hemoglobin A1C, glucose time in range metrics, and adverse events were mixed or inconclusive (i.e., in some studies the use of FGM was associated with improved outcomes, while in other studies it was not).

- While the results summarized in this report generally suggest that the use of FGM is associated with improved clinical outcomes in pediatric populations with type 1 diabetes, the limitations of the included literature should be considered when interpreting these findings.

- No studies were identified that compared the clinical effectiveness of FGM systems with hypoglycemic, hyperglycemia, or signal loss alarms (e.g., FreeStyle Libre 2) to FGM systems without these features (e.g., FreeStyle Libre) in people of any age with diabetes requiring insulin therapy.

\section{Context and Policy Issues}

Diabetes mellitus is a chronic condition in which the body does not produce enough or does not respond normally to insulin, a peptide hormone produced by the pancreas that promotes the absorption of glucose from the blood into cells. There are 3 main types of diabetes: type 1 diabetes, type 2 diabetes, and gestational diabetes. Type 1 diabetes is an autoimmune condition in which the insulin-making beta cells of the pancreas are destroyed. ${ }^{1}$ Often diagnosed in children and young people, common symptoms include frequent urination, increased thirst and hunger, weight loss, blurry vision, tiredness, slow wound healing, and diabetic ketoacidosis. ${ }^{2}$ Type 2 diabetes, which accounts for approximately $90 \%$ of diabetes cases in Canada, ${ }^{3}$ is a complex metabolic disorder where the pancreas is still capable of producing insulin but not in sufficient quantities to meet the body's needs, often a result of insulin resistance. ${ }^{4} \mathrm{~A}$ number of genetic, environmental, and behavioural factors can increase the risk for developing type 2 diabetes, such as age, body weight, diet, use of tobacco or alcohol, and levels of physical activity. ${ }^{5}$ Gestational diabetes is a condition characterized by hyperglycemia that some people may experience during pregnancy. While it typically resolves itself after birth, people who experience gestational diabetes may be at increased risk of developing type 2 diabetes later in life. ${ }^{6}$ Diabetes Canada estimates that 1 in 10 Canadians are diagnosed with type 1 or type 2 diabetes, and that diabetes has direct costs to the health care system of approximately $\$ 3.8$ billion per year. ${ }^{7}$ The incidence and costs associated with diabetes are expected to increase by $2030 .{ }^{7}$

While not the case for all people with diabetes, many individuals with diabetes may require insulin therapy to improve their body's ability to metabolize glucose. Insulin therapy is typically 
delivered using multiple daily insulin injections (MDIl; via vials and syringes or insulin pens), insulin pumps, or using novel approaches such as sensor-augmented pumps or hybrid closed-loop insulin delivery systems. ${ }^{8}$ People with diabetes must check their glucose levels regularly to inform the appropriate doses of insulin to be delivered. Traditionally, blood glucose levels are tested using a blood glucose metre. As part of this process, the individual uses a lancet loaded onto a finger-prick device to puncture their skin and to cause bleeding. A drop of blood is then collected on a test strip and analyzed by the glucose metre. This process is referred to as self-monitoring blood glucose (SMBG). Alternatively, people with diabetes may use flash glucose monitoring (FGM) or continuous glucose monitoring (CGM) devices to inform their insulin dosing decisions. FGM devices, such as the FreeStyle Libre, and CGM devices use an externally-worn glucose sensor with a small filament inserted under the skin, typically on a person's upper arm, to measure interstitial levels of glucose. In the case of FGM devices, the sensor is scanned with a separate reader that transmits and stores glucose readings for the previous 8 hours. FGM systems may provide more than just a glucose reading, such as arrows indicating glucose trends and alarms in cases where hypoglycemia, hyperglycemia, or signal loss are detected. ${ }^{9}$

In December 2019, Ontario Health (Quality) recommended public funding of FGM systems for people with type 1 diabetes who experience recurrent hypoglycemia despite frequent self-monitoring of blood glucose and efforts to optimize insulin management and for people with type 2 diabetes requiring intensive insulin therapy (MDII or continuous subcutaneous insulin infusion) who experience recurrent hypoglycemia despite frequent SMBG and efforts to optimize insulin management. ${ }^{10}$ This recommendation, which was based on the guidance of the Ontario Health Technology Advisory Committee, was informed by a health technology assessment ${ }^{11}$ completed by Ontario Health (Quality), in collaboration with CADTH, that assessed clinical evidence, economic evidence, and patient values and preferences. In short, the findings of the clinical review conducted as part of the health technology assessment suggested that moderate-quality evidence demonstrated that FGM improved diabetes management among adults with well-controlled types 1 diabetes and adults with type 2 diabetes requiring intense insulin therapy. ${ }^{11}$ Of the 6 studies included in the clinical review, only 1 recruited participants younger than 18 years of age. ${ }^{11}$

The objective of the current report is to review the literature regarding the clinical effectiveness of FGM versus SMBG, in pediatric populations with diabetes requiring insulin therapy, published since the health technology assessment. ${ }^{11}$ Additionally, this report aims to summarize clinical evidence that has assessed the effectiveness of alarms available on modernized FGM systems (i.e., FreeStyle Libre 2) in people of all ages with diabetes requiring insulin therapy.

\section{Research Questions}

1. What is the comparative clinical effectiveness of monitoring glycemia with flash glucose monitoring systems, versus self-monitoring with blood strips and lancets, in the pediatric population with diabetes requiring insulin therapy?

2. What is the comparative clinical effectiveness of activating the (hypoglycemia, hyperglycemia, and signal loss) alarms of flash glucose monitoring systems, versus not having or not activating this option, in people with diabetes requiring insulin therapy? 


\section{Methods}

\section{Literature Search Methods}

A limited literature search was conducted by an information specialist on key resources including MEDLINE, the Cochrane Database of Systematic Reviews, the international HTA database, the websites of Canadian and major international health technology agencies, as well as a focused internet search. The search strategy comprised both controlled vocabulary, such as the National Library of Medicine's MeSH (Medical Subject Headings), and keywords. The main search concept was FGM system. No filters were applied to limit the retrieval to study type. Where possible, retrieval was limited to the human population. The search was also limited to English language documents published between April 8, 2018 and March 3, 2021.

\section{Selection Criteria and Methods}

One reviewer screened citations and selected studies. In the first level of screening, titles and abstracts were reviewed and potentially relevant articles were retrieved and assessed for inclusion. The final selection of full-text articles was based on the inclusion criteria presented in Table 1.

\section{Exclusion Criteria}

Articles were excluded if they did not meet the selection criteria outlined in Table 1, they were duplicate publications, or were published before 2018. Systematic reviews in which all relevant studies were captured in other more recent or more comprehensive systematic reviews were excluded. Primary studies retrieved by the search were excluded if they were captured in 1 or more included systematic reviews. Consistent with the Ontario Health

\section{Table 1: Selection Criteria}

\begin{tabular}{|l|l|}
\hline Criteria & Description \\
\hline Population & $\begin{array}{l}\text { Q1: People aged } 18 \text { years or less with diabetes requiring insulin therapy, including those with type 1 or } \\
\text { Q2: People of all ages with diabetes requiring insulin therapy, including those with type 1 or type 2 } \\
\text { diabetes }\end{array}$ \\
\hline Intervention & $\begin{array}{l}\text { Flash glucose monitoring devices: } \\
\text { Q1: FreeStyle Libre and FreeStyle Libre 2 } \\
\text { Q2: FreeStyle Libre 2 (with activation of the [hypoglycemia, hyperglycemia, and signal loss] alarms) }\end{array}$ \\
\hline Comparator & $\begin{array}{l}\text { Q1: Self-monitoring of blood glucose with test strips and lancets } \\
\text { Q2: FreeStyle Libre and FreeStyle Libre 2 (without activation of the hypoglycemia, hyperglycemia, signal } \\
\text { loss) alarms) }\end{array}$ \\
\hline Outcomes & $\begin{array}{l}\text { Clinical effectiveness (e.g., hemoglobin A1C, quality of life, glucose time in range metrics [e.g., time } \\
\text { spent in target glucose ranges], glucose variability, safety [e.g., hypoglycemia events, device-related } \\
\text { adverse events]) }\end{array}$ \\
\hline Study designs & Health technology assessments, systematic reviews, RCTs, and non-randomized studies \\
\hline
\end{tabular}

$\mathrm{RCT}=$ randomized controlled trial. 
(Quality) assessment, ${ }^{11}$ studies focusing exclusively on device accuracy, such as error grid analyses, were also excluded.

\section{Critical Appraisal of Individual Studies}

The included publications were critically appraised by 1 reviewer using the following tools as a guide: A MeaSurement Tool to Assess systematic Reviews 2 (AMSTAR 2) ${ }^{12}$ for systematic reviews and the Downs and Black checklist ${ }^{13}$ for randomized and non-randomized studies. Summary scores were not calculated for the included studies; rather, the strengths and limitations of each included publication were described narratively.

\section{Summary of Evidence}

\section{Quantity of Research Available}

A total of 549 citations were identified in the literature search. Following screening of titles and abstracts, 486 citations were excluded and 63 potentially relevant reports from the electronic search were retrieved for full-text review. Seven potentially relevant publication was retrieved from the grey literature search for full-text review. Of these 70 potentially relevant articles, 54 publications were excluded for various reasons, and 16 publications met the inclusion criteria and were included in this report. These comprised 3 health technology assessments ${ }^{14-16}$ (that each included a systematic review with ${ }^{14,15}$ or without ${ }^{16}$ meta-analysis), 5 systematic reviews ${ }^{17-21}$ ( 3 with meta-analysis ${ }^{17,19,21}$ ), 2 publications s.2,23 $^{22}$ related to 1 randomized controlled trial (RCT), and 6 non-randomized studies. ${ }^{24-29}$ Appendix 1 presents the PRISMA ${ }^{30}$ flow chart of the study selection. Additional references of potential interest are provided in Appendix 5.

\section{Summary of Study Characteristics}

Three relevant health technology assessments (that each included a systematic review with ${ }^{14,15}$ or without ${ }^{16}$ meta-analysis), 5 systematic reviews ${ }^{17-21}$ ( 3 with meta-analysis ${ }^{17,19,21}$ ), 2 publications ${ }^{22,23}$ related to 1 RCT, and 6 non-randomized studies ${ }^{24-29}$ were identified for inclusion in this review. Detailed study characteristics are available in Appendix 2, Table 2 and Table 3.

The health technology assessments ${ }^{14-16}$ and the systematic reviews ${ }^{17-21}$ had objectives and inclusion criteria that were broader than the current report (i.e., wider in scope). All 8 reviews ${ }^{14-21}$ addressed research question 1 and did not provide any evidence to address research question 2; however, these reviews included studies of people of any age, rather than just pediatric populations. Additionally, 7 reviews ${ }^{14,15,17-21}$ were not specific to FGM, but also examined the effectiveness of monitoring glycemia with CGM, delivering insulin with MDII, continuous subcutaneous insulin infusion, sensor-augmented pump therapy, hybrid closedloop therapy, or artificial pancreases, or included studies on FGM versus comparators other than SMBG (e.g., CGM, no comparator). Only the characteristics and results of the subset of relevant studies will be described in this report. 


\section{Study Design}

The systematic review and meta-analysis conducted as part of the health technology assessment by EUnetHTA (2018) $)^{14}$ included RCTs to address their effectiveness question and included RCTs and non-randomized studies to address their safety question. Their literature searches were conducted up to March 15, 2018 and did not impose any restrictions on date of publication. In total, 12 RCTs and 3 prospective non-randomized studies were included in the systematic review. None of these studies were relevant to the current report. The health technology assessment by Health Technology Wales (2018), ${ }^{16}$ which included systematic reviews of RCTs and RCTs published between May 2013 and May 2018, summarized information from 2 RCTs; however, neither of these RCTs was relevant to the current report. The authors of the health technology assessment by Lo Scalzo et al. (2018) ${ }^{15}$ searched for health technology assessment reports, systematic reviews, RCTs, and other controlled studies published up to September 2017. Two RCTs were included in their analysis (neither were relevant to the current report). While all 3 health technology assessments ${ }^{14-16}$ would have included studies relevant to the current report based on their eligibility criteria had they been identified, no results summarized in these reviews addressed the research questions of the current report. This suggested that there may have been a paucity of research on the comparative clinical effectiveness of monitoring glycemia with FGM systems, versus selfmonitoring with blood strips and lancets, in the pediatric population with diabetes requiring insulin therapy published before these health technology assessments.

The authors of the Castellana et al. (2020)17 systematic review and meta-analysis included RCTs and observational studies published up to July 22,2019 . A total of 13 primary studies were included in the systematic review ${ }^{17}$ (2 prospective cohort studies were relevant to the current report). The systematic review by Cowart et al. (2020) ${ }^{18}$ included RCTs published up to November 8, 2019. The review included 9 RCTs; 1 was relevant to the current report. There was no relevant primary study overlap between these 2 systematic reviews. ${ }^{17,18}$ Similar to the health technology assessments, ${ }^{14-16} 3$ systematic reviews ${ }^{19-21}$ ( 2 with meta-analysis ${ }^{19,21}$ ) had eligibility criteria that covered the inclusion criteria for the current report; however, the review authors did not identify any primary studies that met the inclusion criteria for the current report. The review by Dicembrini et al. (2020) ${ }^{19}$ was a systematic review and meta-analysis of RCTs published up to July 31, 2019. De Ridder and colleague ${ }^{20}$ conducted a systematic review of RCTs published up to May 30, 2019. In the Dicembrini et al. (2019) ${ }^{21}$ systematic review and meta-analysis of RCTs, the authors included RCTs published up to September 1 , 2018. While none of these 3 reviews identified studies relevant to the current report, their findings suggest a lack of clinical studies investigating the comparative clinical effectiveness of monitoring glycemia with FGM systems, versus self-monitoring with blood strips and lancets, in pediatric populations with diabetes requiring insulin therapy published before their literature search dates.

The RCT (described in 2 publications ${ }^{22,23}$ ) was a multi-centre, open-label trial that was conducted using a parallel-group design. Participants were enrolled between April 2018 and May 2019. The follow-up duration was 6 months.

All 6 non-randomized studies ${ }^{24-29}$ were prospective, single-centre, single-arm cohort studies. None of these non-randomized studies ${ }^{24-29}$ included a control group; instead, these studies made comparisons from before to after switching from SMBG to FGM with the Freestyle Libre. Study durations were 4 weeks, ${ }^{26,28} 12$ weeks, ${ }^{24,27} 12$ months, ${ }^{29}$ and 24 months. ${ }^{25}$ 


\section{Country of Origin}

The EUnetHTA (2018) ${ }^{14}$ health technology assessment was collaboratively produced by agencies from Austria, Croatia, Italy, Norway, Poland, Portugal, Scotland, and Spain. The other 2 health technology assessments were conducted by groups in Italy ${ }^{15}$ and Wales. ${ }^{16}$

The included systematic reviews were by authors in Belgium, ${ }^{20}$ Italy, ${ }^{17,19,21}$ and the US. ${ }^{18}$ The 3 relevant primary studies included in the systematic reviews ${ }^{17,18}$ were conducted in Belgium, Germany, Ireland, Slovenia, and the UK.

The RCT was conducted in New Zealand. ${ }^{22,23}$ Non-randomized studies were conducted in Belgium, ${ }^{25}$ Saudi Arabia, ${ }^{24,27}$ Singapore, ${ }^{26}$ the $U \mathrm{KK}^{29}$ and the United Arab Emirates. ${ }^{28}$

\section{Patient Population}

The systematic reviews conducted as part of the EUnetHTA (2018) ${ }^{14}$ and Health Technology Wales $(2018)^{16}$ health technology assessments included studies of people, of any age (e.g., adults and children), with type 1, type 2, or gestational diabetes. The health technology assessment by Lo Scalzo et al. (2018) (15 $^{15}$ included studies of children (between the ages of 4 and 18) with type 1 diabetes and studies of adults with type 1 or type 2 diabetes requiring insulin therapy.

The systematic review by Castellana et al. $(2020)^{17}$ included studies of children or adults with type 1 or type 2 diabetes requiring insulin therapy. Cowart et al. (2020) ${ }^{18}$ included studies of children or adults with type 1, type 2 , or gestational diabetes. The reviews by Dicembrini et al. $(2020)^{19}$ and De Ridder et al. (2019) ${ }^{20}$ were specific to those with type 1 diabetes, while the review by Dicembrini et al. (2019) ${ }^{21}$ was specific to people with type 2 diabetes. De Ridder and colleagues ${ }^{20}$ excluded studies of pregnant people.

The RCT 22,23 enrolled 64 youth, between the ages of 13 and 20, with type 1 diabetes (duration of at least 12 months) and mean hemoglobin $\mathrm{A} 1 \mathrm{C} \geq 9 \%$ in the 6 months before enrolment. The non-randomized study by Al Hakey et al. (2020)24 included 187 children between the ages of 13 and 19 years with type 1 diabetes who were on insulin therapy for at least 6 months before enrolment. Charleer et al. (2020)25 enrolled 138 children between the ages of 4 and 18 who had type 1 diabetes with disease duration of at least 3 months. The non-randomized study by Lim et al. (2020) ${ }^{26}$ included 30 participants between the ages of 13 and 18 with type 1 diabetes and a baseline hemoglobin A1C greater than 8.5\%. Al Hakey et al. (2019) ${ }^{27}$ recruited 33 youth between the ages of 14 and 21 with type 1 diabetes who had no previous FGM experience and who had received insulin treatment via MDII or insulin pump for at least 6 months. Deeb et al. (2019) ${ }^{28}$ enrolled 75 children with type 1 diabetes. The non-randomized study by Pintus et al. (2019) ${ }^{29}$ included 52 children between the ages of 5 and 18 with type 1 diabetes. While some of these primary clinical studies ${ }^{22-29}$ included participants above the age of 18, mean participant age was below 18 years in all cases; therefore, these studies were considered eligible.

The total number of relevant participants included in the systematic reviews, ${ }^{17,18}$ the RCT, ${ }^{22,23}$ and the non-randomized studies ${ }^{24-29}$ was 1,034. The mean ages of participants included in the $\mathrm{RCT}^{22,23}$ and the non-randomized studies ${ }^{24-29}$ ranged between 11.6 years ${ }^{28,29}$ and 16.5 years, ${ }^{22,23}$ the proportion of female participants ranged between $33.5 \%{ }^{29}$ and $66.7 \%,{ }^{26}$ and mean baseline hemoglobin A1C values ranged between $7.2 \%{ }^{25}$ and $10.9^{22,23}$ (one study ${ }^{29}$ did not report mean baseline hemoglobin A1C of study participants). 


\section{Interventions and Comparators}

The health technology assessments $\mathrm{s}^{14-16}$ and the systematic reviews ${ }^{17-21}$ included primary studies that examined the clinical effectiveness of monitoring glycemia with FGM systems. One health technology assessment ${ }^{14}$ and 3 systematic reviews ${ }^{19-21}$ also considered other interventions as part of their review, such as CGM devices, ${ }^{14,19-21}$ continuous subcutaneous insulin infusion, ${ }^{21}$ sensor-augmented pump therapy, ${ }^{20}$ hybrid closed-loop insulin delivery systems, ${ }^{20}$ and artificial pancreases. ${ }^{20}$ As for comparators, the health technology assessments and the systematic reviews listed SMBG techniques (e.g., glucose metres), ${ }^{14-21}$ CGM devices, ${ }^{14,15,18,20,21}$ or no comparator ${ }^{17}$ as relevant comparators. Only primary studies that compared FGM versus SMBG techniques were considered relevant to the current report.

The RCT22,23 assigned participants to FGM or to SMBG with a glucometer. All participants included in the non-randomized studies ${ }^{24-29}$ measured glycemia using FGM. The analyses compared outcomes experienced by participants using FGM to outcomes experienced when they were previously using SMBG techniques. None of the included non-randomized studies had a control group; however, within-group comparisons were made from before to after switching to FGM and all participants were using SMBG using the conventional fingerprick method at baseline. The FGM system used in all primary clinical studies ${ }^{22-29}$ was the FreeStyle Libre system (i.e., none of the included studies assessed the effectiveness of the FreeStyle Libre 2).

\section{Outcomes}

Two systematic reviews that included relevant primary studies, ${ }^{17,18} 1 \mathrm{RCT} 22,23$ and 6 non-randomized studies, ${ }^{24-29}$ reported on outcomes relating to the comparative clinical effectiveness of monitoring glycemia with FGM systems in pediatric populations, including hemoglobin A1C, glucose time in range metrics, quality of life, patient satisfaction, fear of hypoglycemia, diabetes distress, self-efficacy, frequency of glucose monitoring, daily insulin dose, mean glucose levels, body mass index (BMI), and adverse events (e.g., hypoglycemic events, serious adverse events, cutaneous adverse events, diabetic ketoacidosis). Outcomes assessed in the health technology assessments and systematic reviews that did not identify any primary studies relevant to the current report are only described in Appendix 2, Table 2.

Measures of hemoglobin A1C included mean changes in hemoglobin A1C throughout study periods ${ }^{17,22-25,29}$ and the proportion of participants with hemoglobin $\mathrm{A} 1 \mathrm{C}$ values at specific thresholds before and after study periods (e.g., $<7.0 \%,<7.5 \%$ ). ${ }^{25}$ Hemoglobin A1C values were expressed as a percentage (National Glycohemoglobin Standardization Program unit) in 4 studies ${ }^{17,22-25}$ and as values in $\mathrm{mmol} / \mathrm{mol}$ (the International Federation of Clinical Chemistry and Laboratory Medicine unit) in 1 study. ${ }^{29}$

Glucose time in range metrics refer to the amount of time (expressed as a percentage of the day or as time in hours and minutes) that an individual's glucose level is within a specified glucose range. Included studies reported on the time spent in euglycemic ranges (e.g., between 3.9 and $10.0 \mathrm{mmol} / \mathrm{L}$ ), ${ }_{17,18}$ hyperglycemic ranges (e.g., $\left.>10.0 \mathrm{mmol} / \mathrm{L}\right),{ }^{17,18}$ and hypoglycemic ranges (e.g., $<3.9 \mathrm{mmol} / \mathrm{L},<3.0 \mathrm{mmol} / \mathrm{L}$ ). ${ }^{17,18}$ Time spent in various ranges while using SMBG was assessed using FGM systems masked to the participant. Glucose values in $\mathrm{mg} / \mathrm{dL}$ were converted to $\mathrm{mmol} / \mathrm{L}$ by multiplying them by 0.05551 to permit consistency in the reporting of the results.

Quality of life was assessed in 4 studies using various tools, including the Pediatric Quality of Life Inventory (PedsQL), 22,23,29 the Diabetes Quality of Life for Youth (DQOLY) scale, ${ }^{25}$ and 
the 5-item WHO Well-Being Index (WHO-5). ${ }^{27}$ The PedsQL is a validated tool that measures health-related quality of life in children and adolescents with type 1 diabetes. ${ }^{29}$ The number of questions and the scoring of questions varies depending on the age of the individual being assessed. Higher scores indicate better quality of life and fewer problems. ${ }^{29}$ The DQOLY scale is a validated tool that includes 3 subscales (i.e., satisfaction, impact, and worry subscales). ${ }^{25}$ Satisfaction scores range from 17 to 85 , with higher scores indicating increased satisfaction. ${ }^{25}$ Impact scores range from 23 to 155, with higher scores indicating higher impact of diabetes on life. ${ }^{25}$ Worry scores range from 13 to 65 , with higher scores indicating increased worries relating to diabetes. ${ }^{25}$ The WHO- 5 questionnaire includes 5 statements that the subject rates between 0 (at no time) and 5 (all of the time). ${ }^{27}$ Higher scores indicate increased well-being. ${ }^{27}$

Patient satisfaction was measured in 3 studies ${ }^{17,22,23,27}$ using the Diabetes Treatment Satisfaction Questionnaire (DTSQ). The DTSQ is a validated tool that consists of 8 items that assess treatment satisfaction and perceived frequency of hyperglycemia and hypoglycemia. Higher scores indicate increased satisfaction. ${ }^{27}$

Fear of hypoglycemia was assessed using the Hypoglycemia Fear Survey (HFS) in 1 RCT 22,23 and 1 non-randomized study. ${ }^{25}$ The HFS is a validated scale that measures behaviours and worries related to fear of hypoglycemia. ${ }^{31}$ It comprises the Behaviour and Worry subscales. Higher scores on the Behaviour and Worry subscales indicate a greater tendency to avoid hypoglycemia and increased worry concerning episodes of hypoglycemia and its consequences, respectively.

One non-randomized study ${ }^{24}$ measured diabetes distress using the 28-item T1-Diabetes Distress Scale (T1-DDS). The T1-DDS comprises 28 items that address 7 concepts of health, including powerlessness, management distress, hypoglycemia distress, negative social perceptions, eating distress, physician distress, and friend/family distress. Each item is scored between 1 (not a problem) and 6 (a very serious problem). Higher overall scores indicate higher levels of diabetes-related distress. ${ }^{24}$

Self-efficacy was evaluated in 1 study ${ }^{26}$ using the Confidence in Diabetes Self-Care (CIDS) questionnaire. The CIDS is a validated 20-item self-report questionnaire designed to measure changes in self-efficacy. Each item is scored on a 5-point Likert scale ranging from 1 to 5. Higher total scores, which are the sum of all item scores, indicate greater self-efficacy. ${ }^{26}$

Frequency of glucose monitoring was evaluated in 3 studies ${ }^{17,22-24}$ and was reported as the mean number of glucose measurements (using SMBG or FGM) per day.

Two studies ${ }^{17,25}$ reported on daily insulin dose as an outcome. Daily insulin doses were expressed in units per day ${ }^{17,25}$ or units per $\mathrm{kg}$ of body weight per day. ${ }^{25}$

Mean glucose levels were measured in 1 study. ${ }^{26}$ Values represented the mean glucose levels throughout the previous 14 days and were expressed in $\mathrm{mmol} / \mathrm{L}$.

Participant BMI was measured as an outcome in 1 study. ${ }^{25} \mathrm{BMI}$ was expressed in $\mathrm{kg} / \mathrm{m}^{2}$ and in standard deviation scores (which are adjusted for participant age). ${ }^{25}$

Outcomes relating to adverse events were recorded in 2 systematic reviews, ${ }^{17,18} 1$ RCT 22,23 and 3 non-randomized studies. ${ }^{24-26}$ Specific outcomes included the number of hypoglycemic events, $, 17,18,24-26$ serious adverse events, ${ }^{18}$ hospitalizations, ${ }^{22,23}$ and cutaneous adverse events, ${ }^{22,23}$ the proportion of participants who experienced diabetic ketoacidosis, ${ }^{22,23}$ 


\section{CADTH}

severe hypoglycemic events, ${ }^{22,23}$ hypoglycemic comas, ${ }^{24,25}$ hospitalizations, ${ }^{25}$ and school absenteeism, ${ }^{25}$ and the days of hospitalization due to diabetes-related complications, ${ }^{25}$ school absenteeism, ${ }^{25}$ and work absenteeism by the parents of participants. ${ }^{25}$

\section{Summary of Critical Appraisal}

Additional details regarding the strengths and limitations of the included publications are provided in Appendix 3, Table 4 and Table 5.

\section{Systematic Reviews}

The 8 systematic reviews ${ }^{14-21}$ (5 with meta-analyses ${ }^{14,15,17,19,21}$ ), 3 of which were conducted as part of health technology assessments, ${ }^{14-16}$ were considered to be of variable methodological quality based on the assessments using AMSTAR $2 .{ }^{12}$ The reviews had clearly defined objectives and primary study eligibility criteria, provided a description of any search restrictions, included a flow chart that illustrated study selection, and the review authors reported on their sources of funding. All but 1 review ${ }^{16}$ provided detailed descriptions of the literature search strategy, including key search terms and dates of searches, increasing the reproducibility of the literature searches. The authors of 5 systematic reviews ${ }^{14,15,17-20}$ conducted electronic searches in multiple databases. Protocols that outlined proposed methods were published for 4 of the systematic reviews, ${ }^{14,17,19,21}$ increasing transparency and decreasing the risk for reporting bias. The methods for article selection, data extraction, and quality assessment were well-documented and were conducted involving multiple reviewers in 2 systematic reviews, ${ }^{14,17}$ decreasing the likelihood for inconsistency in these processes.

Both systematic reviews ${ }^{17,18}$ that included primary studies relevant to the current report described the relevant primary studies in adequate detail and assessed risk of bias using satisfactory techniques. The review by Castellana et al. (2020), ${ }^{17}$ which was the only review that conducted a meta-analysis and identified primary studies relevant to the current report, performed meta-analyses using appropriate methods for the statistical combination of results and assessed heterogeneity when suitable (using I² statistics). However, pooled estimates from this systematic review ${ }^{17}$ could not be extracted for the current report as the pooled data presented in the forest plots included primary studies that were not relevant under our inclusion criteria. Additionally, Castellana and colleagues ${ }^{17}$ assessed publication bias with Egger's test (none was detected, except for change in hemoglobin A1C from baseline to the last available follow-up on FGM).

As for methodological limitations, the authors of none of the included systematic reviews provided justification for their selection of eligible study designs and the literature search strategies did not include grey literature searches, increasing the risk for missing relevant, non-indexed studies. The number of reviewers involved in the article selection, data extraction, or quality assessment processes was unclear or only involved 1 reviewer in 6 reviews. ${ }^{15,16,18-21}$ Only the review by Lo Scalzo et al. (2018) ${ }^{15}$ provided a list of studies excluded after full-text review with reasons for exclusion. Neither of the 2 reviews ${ }^{17,18}$ that identified primary studies relevant to the current report considered the quality or risk of bias among included primary clinical studies when interpreting and discussing the results of the review and the authors did not examine or discuss the impact of heterogeneity on the results of the review in detail. Additionally, the review by Cowart et al. (2020) ${ }^{18}$ did not report on sources of funding for the included primary studies. Finally, the authors of 2 included systematic reviews ${ }^{16,21}$ did not disclose any potential conflicts of interest related to their reviews. 


\section{Randomized Controlled Trials}

The included RCT (described in 2 publications ${ }^{22,23}$ ) had clearly described objectives, intervention, comparator, main outcomes, and participant eligibility criteria. Relevant baseline participant characteristics, such as age, sex, BMI, duration of diabetes, ethnicity, method of insulin delivery, and hemoglobin A1C, were described for both intervention and control groups. While the authors did not test for statistically significant between-group differences for these characteristics, the 2 groups appeared to be balanced, suggesting randomization was successful. In addition to these methodological strengths, compliance with the assigned treatment was reliable, outcome measures were valid, adverse events that may have been a consequence of the intervention were recorded (e.g., cutaneous adverse events), main findings were clearly described, no participants were lost to follow-up, outcomes were assessed at consistent time intervals, and the authors declared that they had no potential conflicts of interest and disclosed their sources of funding (a Cure Kids grant, the Australasian Pediatric Endocrine Group, and the University of Otago). Study participants, care providers, and setting appeared to be representative of the population and care setting of interest.

One methodological limitation of the RCT ${ }^{22,23}$ was that it was an open-label study with no blinding of participants or outcome assessors; therefore, there was a risk for bias in either direction depending on the perceptions and expectations of those involved, although the magnitude of this risk was decreased for outcomes of an objective nature (e.g., hemoglobin A1C). Additionally, the generalizability of the findings from the RCT ${ }^{22,23}$ to Canadian settings was unclear given it was conducted at 3 academic diabetes centres in New Zealand.

\section{Non-Randomized Studies}

The 6 non-randomized studies ${ }^{24-29}$ were considered to be of low methodological quality, mainly due to study design, based on the assessments using the Downs and Black checklist. Methodological strengths common to all 6 studies ${ }^{24-29}$ included: clearly described objectives, interventions, participant eligibility criteria, and main outcomes; participant characteristics such as age, sex or gender, BMI, baseline hemoglobin A1C, insulin delivery method, and duration of diabetes were provided; compliance with the interventions was reliable; outcome measures were valid; main findings were clearly reported; the number and characteristics of participants lost to follow-up were described; and care providers and care settings appeared to be representative of the settings of interest, increasing external validity. The authors of 4 non-randomized studies ${ }^{24,26-28}$ declared that they had no potential conflicts of interest. Sources of funding were reported in 4 studies ${ }^{24-27}$ and in all cases were considered unlikely to have had an effect on the findings of the studies.

There were significant methodological limitations identified for each of the 6 non-randomized studies. ${ }^{24-29}$ None of these studies ${ }^{24-29}$ compared outcomes in a group of participants who received FGM with the FreeStyle Libre versus a control group of participants who used SMBG. Instead, these studies ${ }^{24-29}$ used quasi-experimental pretest and post-test designs that compared outcomes experienced by a single cohort of patients from before to after switching from SMBG to FGM. As a result, the findings of these studies ${ }^{24-29}$ are susceptible to numerous forms of bias that threaten both internal and external validity. Any outcomes observed in study participants should not be attributed to FGM alone, as there are many uncontrolled factors that may have contributed to the findings of these studies. ${ }^{24-29}$ Additionally, all 6 studies ${ }^{24-29}$ were open-label with no blinding of study participants or outcome assessors. While study participants generally appeared to be representative of the populations of interest, 2 studies ${ }^{24,26}$ recruited participants using a convenience sample; therefore, it was unclear whether participants from these studies were truly representative of the populations 
they were sampled from. In 3 non-randomized studies ${ }^{25,26,29}$ it was unclear what intervention participants were using to monitor glucose levels before switching to FGM; however, it was assumed to have been SMBG, and therefore these studies were considered eligible for inclusion in the current report. Of the 52 children included in the Pintus et al. (2019) ${ }^{29}$ study, 22 (i.e., $42 \%$ of the study population) were unable to complete the study. Similarly, a large portion (38 out of $122 ; 31.1 \%$ ) of the participants in the study by Charleer et al. $(2020)^{25}$ did not provide data for the primary outcome after 24 months of follow-up; the results of these studies ${ }^{25,29}$ are at risk of attrition bias. The authors of 2 non-randomized studies did not disclose their potential conflicts of interest ${ }^{29}$ or disclosed many financial and non-financial conflicts of interest with industry. ${ }^{25}$ Similarly, the authors of 2 studies ${ }^{28,29}$ did not report on their sources of funding. Finally, there were some additional concerns relating to the generalizability of the findings to Canadian settings as all the included non-randomized studies $^{24-29}$ were conducted as single-centre studies outside of Canada.

\section{Summary of Findings}

The overall findings of the included studies are highlighted below. Detailed summaries of the main findings and authors' conclusions are available in Appendix 4, Table 6 and Table 7.

\section{Clinical Effectiveness of FGM Systems Versus SMBG in Pediatric Populations Hemoglobin A1C}

Two primary studies included in the Castellana et al. (2020) ${ }^{17}$ systematic review, 1 RCT, ${ }^{22,23}$ and 3 non-randomized studies ${ }^{24,25,29}$ reported on measures of hemoglobin A1C. Of these 6 primary studies, 2 studies ${ }^{17,29}$ observed statistically significant improvements in hemoglobin A1C associated with the use of FGM compared to SMBG, 1 study ${ }^{25}$ observed statistically significant deteriorations in hemoglobin $\mathrm{A} 1 \mathrm{C}$ associated with the use of FGM compared to SMBG, and 3 studies ${ }^{17,22-24}$ did not report any significant differences in hemoglobin A1C between FGM and SMBG.

The authors of the Campbell et al. (2018) study included in the Castellana et al. (2020)17 systematic review noted that participants' mean hemoglobin A1C decreased from $7.9 \%$ (standard deviation $[\mathrm{SD}]=1.0 \%$ ) at baseline (while using SMBG) to $7.5 \%(\mathrm{SD}=0.9 \%$ ) after FGM. This was a statistically significant change of $-0.40 \%$ (95\% confidence interval [CI] $=-0.70 \%$ to $-0.10 \%)$. Participants of the non-randomized study by Pintus et al. $(2019)^{29}$ had significantly decreased hemoglobin A1C values 3 months after switching to FGM compared to 12 months before switching ( $62 \mathrm{mmol} / \mathrm{mol}$ versus $59.5 \mathrm{mmol} / \mathrm{mol} ; \mathrm{P}=0.040), 6$ months before switching $(61.9 \mathrm{mmol} / \mathrm{mol}$ versus $59.5 \mathrm{mmol} / \mathrm{mol} ; \mathrm{P}=0.040)$, and $3 \mathrm{months}$ before switching ( $65.2 \mathrm{mmol} / \mathrm{mol}$ versus $59.5 \mathrm{mmol} / \mathrm{mol} ; \mathrm{P}=0.012)$. There were no significant differences in mean hemoglobin A1C values 6 months after switching to FGM or 12 months after switching to FGM when compared to 3 months before switching to FGM.

Charleer et al. (2020) ${ }^{25}$ reported significant decreases in the proportion of children with hemoglobin A1C less than $7.5 \%$ and less than $7.0 \%$ and a statistically significant increase in mean hemoglobin A1C values during their 24-month follow-up period. The proportion of participants who had hemoglobin A1C values less than $7.5 \%$ was $66.7 \%$ at baseline (while using SMBG), 67.9\% after 6 months of FGM (P value versus baseline was non-significant), $54.5 \%$ after 12 months of FGM (P value versus baseline was 0.006 ), and $59.0 \%$ after 24 months of FGM (P value versus baseline was 0.019). Similarly, the proportion of participants who had hemoglobin A1C values less than $7.0 \%$ was $47.8 \%$ at baseline (while using SMBG), $27.6 \%$ after 12 months of FGM ( $P$ value versus baseline was $<0.0001$ ), and $31.1 \%$ after 
24 months of FGM (P value versus baseline was 0.001). Mean hemoglobin A1C values at baseline were $7.16 \%(95 \% \mathrm{Cl}, 7.0 \%$ to $7.3 \%), 7.26 \%(95 \% \mathrm{Cl}$ was presented in a figure; exact value could not be ascertained) after 6 months of FGM, (P value versus baseline was nonsignificant), $7.62 \%$ ( $95 \% \mathrm{Cl}, 7.4 \%$ to $7.8 \%$ ) after 12 months of FMG (P value versus baseline was $<0.0001)$, and $7.56 \%(95 \% \mathrm{Cl}, 7.4 \%$ to $7.8 \%$ ) after 24 months of FGM (P versus baseline was $<0.0001$ ).

There were no statistically significant differences in measures of hemoglobin A1C observed in the Messaaoui et al. (2019) study included in the Castellana et al. (2020)17 systematic review or in the RCT. ${ }^{22,23}$ The non-randomized study by Al Hakey et al. (2020)24 reported a decrease in mean hemoglobin $\mathrm{A} 1 \mathrm{C}$ from $8.2 \%(\mathrm{SD}=2.3 \%)$ at baseline to $7.9 \%(\mathrm{SD}=2.1 \%)$ after 12 weeks of FGM use; however, the statistical significance of this finding was not reported.

\section{Glucose Time in Range Metrics}

Glucose time in range metrics were assessed in 2 cohort studies included in the Castellana et al. (2020) ${ }^{17}$ systematic review and 1 RCT included in the Cowart et al. (2020) ${ }^{18}$ systematic review. The findings from 1 study suggested that FGM was associated with improvements to time in range metrics; 2 studies suggested there were no statistically significant differences between FGM and SMBG with respect to time in range metrics.

Messaaoui et al. (2019), included in the Castellana et al. (2020) ${ }^{17}$ systematic review, noted that participants of their study spent $4.32(S D=1.68)$ hours per day with a glucose value less than $3.9 \mathrm{mmol} / \mathrm{L}$ at baseline while using SMBG compared to $3.6(\mathrm{SD}=1.92)$ hours per day while using FGM. The mean difference in time spent in hypoglycemia was statistically significant $\left(-0.72[95 \% \mathrm{Cl},-1.02\right.$ to -0.42$]$ hours per day). ${ }^{17}$

As summarized in the systematic review by Castellana et al. (2020), ${ }^{17}$ participants of the Campbell et al. (2018) study spent $11.1(\mathrm{SD}=3.3$ ) hours per day with glucose values in the target range (i.e., between 3.9 and $10.0 \mathrm{mmol} / \mathrm{L}$ ) while using FGM compared to $10.1(\mathrm{SD}=3.0)$ hours per day while using SMBG. This difference was not statistically significant. ${ }^{17}$ There were also no statistically significant differences in the mean time spent in hypoglycemia (i.e., $<3.9$ $\mathrm{mmol} / \mathrm{L}$ ) or hyperglycemia (i.e., $>10.0 \mathrm{mmol} / \mathrm{L}$ ). ${ }^{17}$ Similarly, the authors of the Piona et al. (2018) RCT (as summarized in the systematic review by Cowart and colleagues ${ }^{18}$ ) did not observe statistically significant differences in the mean proportion of time spent with glucose values between 3.9 and $10.0 \mathrm{mmol} / \mathrm{L}(50.9 \%$ versus $50.8 \% ; P=0.64)$, greater than 10.0 $\mathrm{mmol} / \mathrm{L}(45.2 \%$ versus $44.7 \% ; \mathrm{P}=0.69)$, or less than $3.0 \mathrm{mmol} / \mathrm{L}(1.3 \%$ versus $1.4 \% ; \mathrm{P}=0.98)$, between groups of participants who were assigned to FGM or SBMG. ${ }^{18}$

\section{Quality of Life}

One RCT ${ }^{22,23}$ and 3 non-randomized studies ${ }^{25,27,29}$ assessed quality of life. In all 4 studies the use of FGM was associated with statistically significant improvements in some measures of quality of life compared to SMBG.

Participants of the RCT ${ }^{22,23}$ who were treated with FGM reported statistically significantly larger improvements in mean diabetes subscale scores of the PedsQL Diabetes compared to those who received SMBG throughout the 6-month follow-up period. There were no statistically significant between-group differences for PedsQL Generic total scores, PedsQL Diabetes total scores, or for scores on any other PedsQL Diabetes subscales (i.e., treatment I subscale, treatment II subscale, worry subscale, communication subscale). Within the non-randomized study by Charleer et al. (2020), ${ }^{25}$ mean DQOLY satisfaction subscale scores reported by participants improved from $68.8(95 \% \mathrm{Cl}, 67.4$ to 70.3$)$ at baseline (before 
starting FMG), to 71.9 ( $95 \% \mathrm{Cl}, 70.3$ to 73.4$) 6$ months after switching to FGM (P value versus baseline was < 0.001$)$ and $71.2(95 \% \mathrm{Cl}, 69.8$ to 72.7$) 12$ months after switching to FGM ( $P$ value versus baseline was $<0.001)$. There were also significant improvements in mean DQOLY impact subscale scores reported by participants at 6 months compared to baseline (52.1 versus $50.5 ; P<0.05)$. There were no significant differences in mean DQOLY worry subscale scores at 6 months, 12 months, or 24 months after switching to FGM compared to baseline. Al Hakey et al. (2019) ${ }^{27}$ noted that mean WHO-5 scores from participants in their study statistically significantly improved from $11.3(S D=4.2)$ at baseline to $23.4(S D=1.6)$ after 12 weeks of FGM use $(P<0.001)$. Similarly, mean PedsQL total scores of participants in the non-randomized study Pintus et al. (2019) ${ }^{29}$ improved from 75.6 at baseline (while using $S M B G)$ to 82.53 months after switching to FGM. This difference was statistically significant $(P=0.014)$. Significant improvements were also reported for mean PedsQL symptoms scores and mean PedsQL treatment barrier scores between baseline measurements and 3 months after switching to FGM.

\section{Patient Satisfaction}

Information on the effect of FGM on patient satisfaction was available from 1 primary study included in 1 systematic review, ${ }^{17} 1$ RCT, ${ }^{22,23}$ and 1 non-randomized study. ${ }^{27}$ FGM was associated with improved patient satisfaction across all 3 studies.

The findings of the Campbell et al. (2018) study, which was summarized in the systematic review by Castellana et al. (2020), ${ }^{17}$ suggested that there were statistically significant improvements in mean DTSQ scores from baseline to final follow-up, as measured with both the teen and parent versions of the tool. Similarly, participants in the RCT ${ }^{22,23}$ who were assigned to FGM had significantly improved DTSQ scores after the 6-month follow-up period compared to a group of patients who measured glycemia with SMBG $(P=0.048)$. Al Hakey et al. (2019) ${ }^{27}$ observed an increase in mean DTSQ scores from $14.4(S D=6.0)$ at baseline to $31.7(S D=1.9)$ after 12 weeks of FGM. This change in DTSQ scores was statistically significant $(P<0.001)$.

\section{Fear of Hypoglycemia}

Fear of hypoglycemia was assessed in the RCT ${ }^{22,23}$ and 1 non-randomized study. ${ }^{25}$ The authors of the RCT ${ }^{22,23}$ did not observe any statistically significant differences in mean HFS scores between participants assigned to FGM and those assigned to SMBG after 6 months of therapy. Similarly, there were no statistically significant changes in mean HFS scores of participants in the Charleer et al. (2020 ${ }^{25}$ study from baseline (while using SMBG) throughout the 24-month study period when participants were using FGM.

\section{Diabetes Distress}

The authors of the non-randomized study by Al Hakey et al. (2020) ${ }^{24}$ measured diabetes distress in their study population. Mean T1-DDS total scores improved from 2.93 (SD was presented in a figure; exact value could not be ascertained) at baseline to 2.46 (SD was presented in a figure; exact value could not be ascertained) 12 weeks after switching to FGM. This difference was statistically significant $(P=0.001)$. Additionally, there were statistically significant improvements in mean scores for each subdomain of the T1-DDS (i.e., powerlessness subdomain, management distress subdomain, hypoglycemia distress subdomain, negative social perceptions subdomain, eating distress subdomain, physician distress subdomain, friend or family distress subdomain). 


\section{Self-Efficacy}

Measures of self-efficacy were reported in 1 non-randomized study. ${ }^{26}$ Throughout this study, ${ }^{26}$ mean total CIDS scores improved from $78.14(S D=12.91)$ at baseline while participants were using SMBG to $82.23(S D=12.79) 4$ weeks after switching to FGM. The overall change in mean scores was $4.09(S D=9.47)$, which was a statistically significant improvement $(P=0.05)$.

\section{Frequency of Glucose Monitoring}

Frequency of glucose monitoring was assessed as an outcome in 2 primary studies summarized in 1 systematic review, ${ }^{17}$ the $\mathrm{RCT}^{22,23}$ and 2 non-randomized studies. ${ }^{24,28}$

Campbell et al. (2018) and Messaaoui et al. (2019) (as summarized in the systematic review by Castellana and colleagues ${ }^{17}$ ) both observed statistically significant decreases in the number of SMBG measurements per day associated with the use of FGM. While these results did not reflect the overall frequency of glucose checks as they did not consider the frequency of monitoring glucose with FGM, they do suggest participants relied less on SMBG measurements.

Participants of the RCT ${ }^{22,23}$ who were assigned to FGM had a significantly increased frequency of glucose checks (interstitial and capillary) compared to the group of participants who were assigned to SMBG. The difference between the 2 group was statistically significant $(P<0.001)$.

Within the non-randomized study by Deeb et al. (2019), ${ }^{28}$ the median of the average daily number of glucose checks increased from 2.87 (interquartile range [IQR], 1 to 6) at baseline while using SMBG to 11 (IQR, 3 to 44) at final follow-up after switching to FGM. This increase was statistically significant $(P<0.001)$. The authors of the Al Hakey et al. $(2020)^{24}$ nonrandomized study noted that the frequency of glucose checks per day increased from 2.1 $(S D=1.2)$ at baseline while participants were using SMBG to $6.7(S D=1.7) 12$ weeks after switching to FGM. The statistical significance of this difference was not reported.

\section{Insulin Dose}

Total daily insulin dose was recorded as an outcome in 1 primary study in the Castellana et al. $(2020)^{17}$ systematic review and 1 non-randomized study. ${ }^{25}$

The authors of the non-randomized study by Charleer et al. $(2020)^{25}$ reported mean total daily doses of insulin throughout their 24-month study period. After 12 months of FGM, participants were using significantly increased units of insulin per day compared to baseline. After 24 months of FGM, participants were using significantly decreased units of insulin per kilogram body weight per day compared to baseline. There were no statistically significant differences in mean total daily dose of insulin at other follow-up points.

In the study by Campbell et al. (2018), there were no statistically significant changes in mean total daily insulin doses from baseline, when participants were using SMBG, to final follow-up after participants had switched to FGM. ${ }^{17}$

\section{Glucose Levels}

Mean glucose levels were reported in 1 included non-randomized study. ${ }^{26}$ The findings of this study ${ }^{26}$ suggested that the use of FGM over the 4-week study period was not 
associated with significant changes in mean glucose levels throughout the previous 14 days compared to SMBG.

\section{Body Mass Index}

Participant BMI was assessed as an outcome in the non-randomized study by Charleer et al. (2020)..$^{25}$ The authors noted that the mean BMI of participants statistically significantly increased by $1.8 \mathrm{~kg} / \mathrm{m}^{2}$ from baseline when participants were using SMBG to final follow-up, 24 months after switching to FGM $(P<0.0001)$. This increase in $B M I$ remaining significant after adjusting for age (i.e., when BMI was expressed in standard deviation scores).

\section{Adverse Events}

Information on the comparative clinical effectiveness of FGM versus SMBG in pediatric populations with respect to adverse events was available from 2 systematic reviews, ${ }^{17,18} 1$ $\mathrm{RCT},{ }^{22,23}$ and 3 non-randomized studies. ${ }^{24-26}$

Participants of the study by Campbell et al. (2018), which was summarized in the systematic review by Castellana et al. (2020), ${ }^{17}$ did not experience significant changes in the mean number of hypoglycemic events per day from before to after switching to FGM. The authors of the study by Piona et al. (2018), which was a RCT with a 14-day follow-up period, noted that no participants of their study experienced severe hypoglycemic events or other serious adverse events. ${ }^{18}$

Findings from the RCT by Boucher et al. (2020)22 and Marsters et al. (2020)23 suggested that participants who were assigned to FGM were more likely to experience cutaneous adverse events throughout the 6-month study period than those who were assigned to SMBG. There were no statistically significant between-group differences in the proportion of participants who experienced at least 1 episode of diabetic ketoacidosis, the proportion of participants who experienced severe hypoglycemic events, the total number of FGM-associated or SMBG-associated cutaneous adverse events, the average number of symptoms reported per cutaneous adverse events, and in the frequency of cutaneous adverse event reports that were rated mild, moderate, or severe.

Participants in the non-randomized study by Al Hakey et al. (2020) ${ }^{24}$ experienced an average of 6.3 (SD = 1.7) hypoglycemic events per month while using SMBG compared to 4.7 (SD $=1.9$ ) hypoglycemic events per month after switching to FGM; however, the statistical significance of this change was not reported. The authors of the non-randomized study by Charleer et al. (2020) ${ }^{25}$ reported that participants had fewer days of hospitalizations due to hypoglycemia and/or ketoacidosis and days of hospitalization due to hypoglycemia in the previous 12 months per 100 patient years after 12 months of FGM compared to baseline when participants were using SMBG. Similarly, participants had significantly decreased number of days of school absenteeism and decreased number of days of work absenteeism by their parents per 100 patient years in the previous 12 months after using FGM for 24 months compared to baseline. There were no significant changes in the proportion of participants who experienced hospitalizations due to hypoglycemia and/or ketoacidosis, the proportion of participants who experienced hospitalizations due to hypoglycemia, the proportion of participants who experienced hospitalizations due to ketoacidosis, the days of hospitalizations due to ketoacidosis in the previous 12 months per 100 patient years, the proportion of participants who required help from a third party due to hypoglycemia in the previous 6 months, the number of hypoglycemic events that required help from a third party in the previous 12 months per 100 patient years, the proportion of participants who experienced 


\section{CADTH}

hypoglycemic comas in the previous 6 months, the number of hypoglycemic comas in the previous 12 months per 100 patient years, the proportion of participants who experienced school absenteeism in the previous 6 months, and the proportion of parents of participants who experienced work absenteeism in the previous 6 months from baseline to any follow-up period throughout the trial after switching to FGM. Contrary to the previous non-randomized studies, the findings from the non-randomized study by Lim et al. (2020) ${ }^{26}$ indicated that the use of FGM was associated with an increase in the mean number of hypoglycemic events experienced by participants in the previous 14 days compared to baseline. This was the case after 2 weeks of FGM use and after 4 weeks of FGM use.

Overall, the identified literature made mixed conclusions regarding the comparative clinical effectiveness of FGM versus SMBG with respect to adverse events. One study suggested that FGM may be associated with decreased adverse events per 100 patient years, ${ }^{25} 1$ study $^{17}$ suggested that there may be no difference in adverse events between FGM and SMBG, and 2 studies ${ }^{22,23,26}$ suggested that FGM may be associated with increased adverse events. The authors of 2 studies ${ }^{18,24}$ did not test the statistical significance of their findings related to adverse events.

\section{Clinical Effectiveness of (Hypoglycemia, Hyperglycemia, and Signal loss) Alarms in FGM Systems}

No relevant evidence regarding the comparative clinical effectiveness of activating the (hypoglycemia, hyperglycemia, and signal loss) alarms of FMG systems, versus not having or not activating this option, in people with diabetes requiring insulin therapy was identified; therefore, no summary can be provided.

\section{Limitations}

While 3 health technology assessments ${ }^{14-16}$ and 5 systematic reviews ${ }^{17-21}$ were included in this report, only 2 of these evidence syntheses ${ }^{17,18}$ identified literature assessing the comparative clinical effectiveness of measuring glycemia with FGM systems versus SMBG in pediatric populations with diabetes requiring insulin therapy.

The authors of 3 non-randomized studies ${ }^{25,26,29}$ were not explicit in stating that all study participants were measuring glycemia using SMBG before switching to FGM; however, based on the authors' descriptions of their methods this was assumed to be the case and these studies ${ }^{25,26,29}$ were judged to be relevant to the current report.

None of the included studies ${ }^{17,18,22-29}$ discussed minimal clinically important difference values for any of the outcomes measured using continuous scales (e.g., patient satisfaction measured with DTSQ scores, fear of hypoglycemia measured with HFS scores, diabetes distress measured with T1-DDS scores, quality of life measured with PedsQL or DQOLY scores). It is unclear if any of the reported changes in mean scores on these scales reflect clinically meaningful differences.

Participants of the included studies ${ }^{17,18,22-29}$ were diagnosed with type 1 diabetes. The clinical effectiveness of FGM systems in pediatric populations with other forms of diabetes requiring insulin therapy, such as type 2 diabetes, is unclear. 
All included primary studies ${ }^{22-29}$ conducted multiple statistical tests (e.g., for multiple outcomes tested at varying follow-up periods) but did not adjust for multiplicity. As a result, there may be potential inflation of the type I error rate in these studies. ${ }^{22-29}$

No relevant studies that assessed the clinical effectiveness of the FreeStyle Libre 2 FGM system were identified. Additionally, no evidence regarding the comparative clinical effectiveness of activating the (hypoglycemia, hyperglycemia, and signal loss) alarms of FGM systems, versus not having or not activating this option, in people with diabetes requiring insulin therapy was identified; therefore, it is unclear if the use of these alarms provides additional clinical benefit.

While several studies had relatively long follow-up durations (6 months, ${ }^{22,23} 12$ months, ${ }^{29} 56$ weeks, ${ }_{17}^{17}$ and 24 months ${ }^{25}$ ), most of the included studies did not observe participants for more than 3 months. ${ }^{17,18,24,26-28}$ There is some uncertainty in the long-term effectiveness and safety of monitoring glycemia with FGM systems in pediatric populations with diabetes requiring insulin therapy.

All primary studies $17,18,22-29$ included and summarized in this report were conducted outside of North America. The generalizability of the findings to Canadian settings is unclear.

\section{Conclusions and Implications for Decision- or Policy-Making}

This review comprised 8 systematic reviews ${ }^{14-21}$ ( 3 of which were conducted as part of health technology assessments ${ }^{14-16}$ ) that summarized a total of 3 relevant primary studies, 1 $\mathrm{RCT}_{1}^{22,23}$ and 6 non-randomized studies ${ }^{24-29}$ regarding the comparative clinical effectiveness of monitoring glycemia with FGM systems, versus SMBG, in pediatric populations with diabetes requiring insulin therapy. No literature addressing the comparative clinical effectiveness of activating the hypoglycemia, hyperglycemia, and signal loss alarms of FGM systems, versus not having or not activating this option, in people with diabetes requiring insulin therapy was identified.

Based on the evidence summarized in this review, FGM with the FreeStyle Libre appears to improve quality of life, ${ }^{22,23,25,27,29}$ patient satisfaction, ${ }^{17,22,23,27}$ diabetes distress, ${ }^{24}$ self-efficacy, ${ }^{26}$ and frequency of glucose monitoring ${ }^{22-24,28}$ compared to SMBG in pediatric populations with type 1 diabetes. Some of these findings are based on the results of 1 primary clinical study (e.g., diabetes distress and self-efficacy). The evidence for measures of hemoglobin A1C, 17,22${ }^{25,29}$ glucose time in range metrics, ${ }^{17,18}$ and adverse events ${ }^{17,18,22-26}$ was mixed. In some studies, FGM was associated with significant improvements to these outcomes, while in other studies there were no differences between treatment with FGM and SMBG. SMBG use was associated with improvements to some measures of adverse events compared to FGM in 2 studies. ${ }^{22,23,26} \mathrm{FGM}$ does not appear to impact fear of hypoglycemia, ${ }^{22,23,25}$ daily insulin dose, ${ }^{17,25}$ or mean glucose levels ${ }^{26}$ compared to SMBG.

The limitations of the included literature (e.g., the use of single-arm pretest and post-test study designs, the variable quality of included primary studies, uncertainty in whether statistically significant changes in outcomes measured using continuous scales translate into clinically meaningful differences, and unclear generalizability to Canadian settings) should be 
considered when interpreting the findings of this report. Future studies that directly compare outcomes of pediatric populations treated with FGM versus a control group of participants monitoring glycemia using SMBG, particularly studies that report on outcomes that currently have mixed or inconclusive findings (e.g., hemoglobin A1C, glucose time in range metrics, adverse events), would help to better understand the role of FGM in the management of pediatric diabetes. Additionally, research investigating the use of FGM in pediatric populations with type 2 diabetes and research on the benefit of FGM systems equipped with alarms (e.g., the FreeStyle Libre 2) for people of any age with diabetes requiring insulin therapy would help to address some of the knowledge gaps identified in this review. 


\section{References}

1. Simmons KM, Michels AW. Type 1 diabetes: A predictable disease. World J Diabetes. 2015;6(3):380-390. PubMed

2. DiMeglio LA, Evans-Molina C, Oram RA. Type 1 diabetes. Lancet (London, England). 2018;391(10138):2449-2462. PubMed

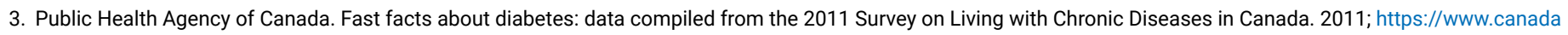
.ca/content/dam/phac-aspc/migration/phac-aspc/cd-mc/publications/diabetes-diabete/pdf/diabetes-facts-faits-2011-eng.pdf. Accessed 2021 Mar 31.

4. Blaslov K, Naranđa FS, Kruljac I, Renar IP. Treatment approach to type 2 diabetes: Past, present and future. World J Diabetes. 2018;9(12):209-219. PubMed

5. Bellou V, Belbasis L, Tzoulaki I, Evangelou E. Risk factors for type 2 diabetes mellitus: an exposure-wide umbrella review of meta-analyses. PLoS One. 2018;13(3):e0194127-e0194127. PubMed

6. Centers for Disease Control and Prevention. Gestational diabetes. 2019; https://www.cdc.gov/diabetes/basics/gestational.html. Accessed 2021 Mar 31.

7. Diabetes in Canada: backgrounder. Ottawa (ON): Diabetes Canada; 2020: https://diabetes.ca/DiabetesCanadaWebsite/media/Advocacy-and-Policy/Backgrounder/ 2020_Backgrounder_Canada_English_FINAL.pdf. Accessed 2021 Mar 31.

8. Shah RB, Patel M, Maahs DM, Shah VN. Insulin delivery methods: Past, present and future. Int J Pharm Investig. 2016;6(1):1-9. PubMed

9. Mancini G, Berioli MG, Santi E, et al. Flash glucose monitoring: a review of the literature with a special focus on type 1 diabetes. Nutrients. 2018;10(8):992. PubMed

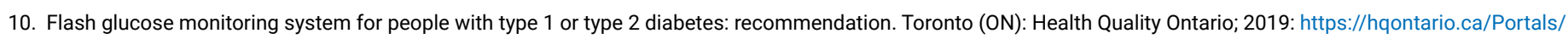
0/Documents/evidence/reports/recommendation-flash-glucose-monitoring-system-en.pdf. Accessed 2021 Mar 31.

11. Ontario Health. Flash glucose monitoring system for people with type 1 or type 2 diabetes: a health technology assessment. Ont Health Technol Assess Ser. 2019;19(8):1-108. PubMed

12. Shea BJ, Reeves BC, Wells G, et al. AMSTAR 2: a critical appraisal tool for systematic reviews that include randomised or non-randomised studies of healthcare interventions, or both. BMJ. 2017;358:j4008. PubMed

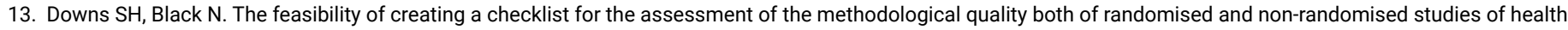
care interventions. J Epidemiol Community Health. 1998;52(6):377-384. PubMed

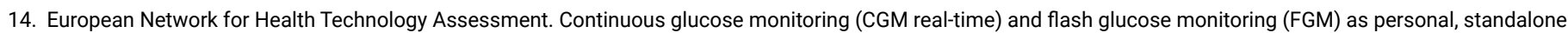
systems in patients with diabetes mellitus treated with insulin. (Rapid assessment of other technologies using the HTA Core Model for rapid relative effectiveness assessment; project ID: OTJA08) 2018; https://www.eunethta.eu/wp-content/uploads/2018/07/OTJA08_CGM-real-time-and-FGM-aspersonal2c-standalone-systems-in -patients-with-diabetes-mellitus-treatedwith-insulin.pdf. Accessed 2021 Mar 31.

15. Lo Scalzo A, Abraha I, Bonomo MA, et al. Flash continuous glucose monitoring systems for diabetes subjects in insulin therapy. (Rapid HTA report). Rome (Italy): Italian Ministry of Health and Agenas; 2018: http://www.salute.gov.it/imgs/C_17_ReportDispositivi_1_documentolnglese_inglese_itemName_0_documentoENG.pdf. Accessed 2021 Mar 31.

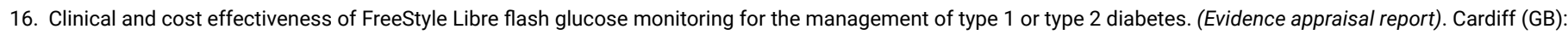
Health Technology Wales; 2018: https://www.healthtechnology.wales/wp-content/uploads/2018/11/EAR004-FreeStyle-libre.pdf. Accessed 2021 Mar 31.

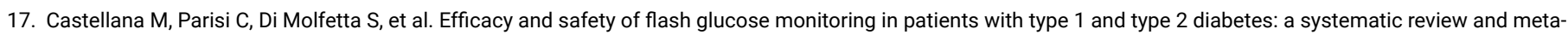
analysis. BMJ open diabetes res. 2020;8(1):06.

18. Cowart K, Updike W, Bullers K. Systematic review of randomized controlled trials evaluating glycemic efficacy and patient satisfaction of intermittent-scanned continuous glucose monitoring in patients with diabetes. Diabetes Technol Ther. 2020;22(5):337-345. PubMed

19. Dicembrini I, Cosentino C, Monami M, Mannucci E, Pala L. Effects of real-time continuous glucose monitoring in type 1 diabetes: a meta-analysis of randomized controlled trials. Acta Diabetol. 2020;13:13. PubMed

20. De Ridder F, den Brinker M, De Block C. The road from intermittently scanned continuous glucose monitoring to hybrid closed-loop systems. Part B: results from randomized controlled trials. Ther Adv Endocrinol Metab. 2019;10:2042018819871903. PubMed

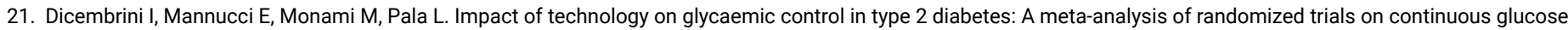
monitoring and continuous subcutaneous insulin infusion. Diabetes Obes Metab. 2019;21(12):2619-2625. PubMed

22. Boucher SE, Gray AR, Wiltshire EJ, et al. Effect of 6 months of flash glucose monitoring in youth with type 1 diabetes and high-risk glycemic control: a randomized controlled trial. Diabetes Care. 2020;43(10):2388-2395. PubMed

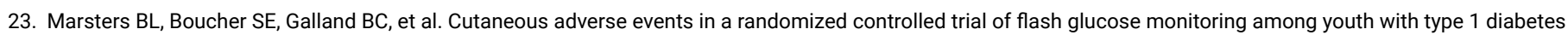
mellitus. Pediatr Diabetes. 2020;21(8):1516-1524. PubMed

24. Al Hayek AA, Robert AA, Al Dawish MA. Effectiveness of the freestyle libre flash glucose monitoring system on diabetes distress among individuals with type 1 diabetes: a prospective study. Diabetes Ther. 2020;11(4):927-937. PubMed

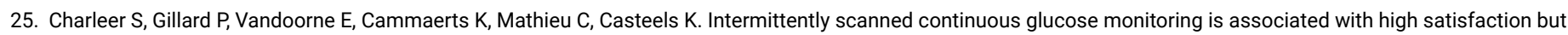
increased HbA1c and weight in well-controlled youth with type 1 diabetes. Pediatr Diabetes. 2020;21(8):1465-1474. PubMed 
26. Lim STJ, Huang F, Lek N, Pereira K. Flash continuous home glucose monitoring to improve adherence to self-monitoring of blood glucose and self-efficacy in adolescents with type 1 diabetes. Clin Diabetes. 2020;38(2):152-158. PubMed

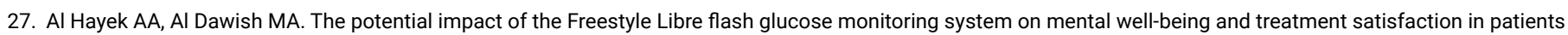
with type 1 diabetes: a prospective study. Diabetes Ther. 2019;10(4):1239-1248. PubMed

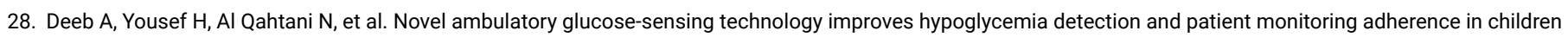
and adolescents with type 1 diabetes. J Diabetes Metab Disord. 2019;18(1):1-6. PubMed

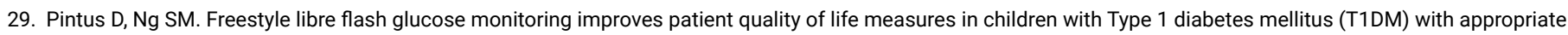
provision of education and support by healthcare professionals. Diabetes Metab Syndr. 2019;13(5):2923-2926. PubMed

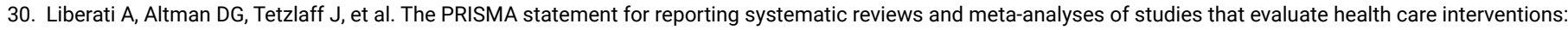
explanation and elaboration. J Clin Epidemiol. 2009;62(10):e1-e34. PubMed

31. Gonder-Frederick LA, Schmidt KM, Vajda KA, et al. Psychometric properties of the hypoglycemia fear survey-II for adults with type 1 diabetes. Diabetes Care. 2011;34(4):801-806. PubMed 


\section{Appendix 1: Selection of Included Studies}

\section{Figure 1: Selection of Included Studies}

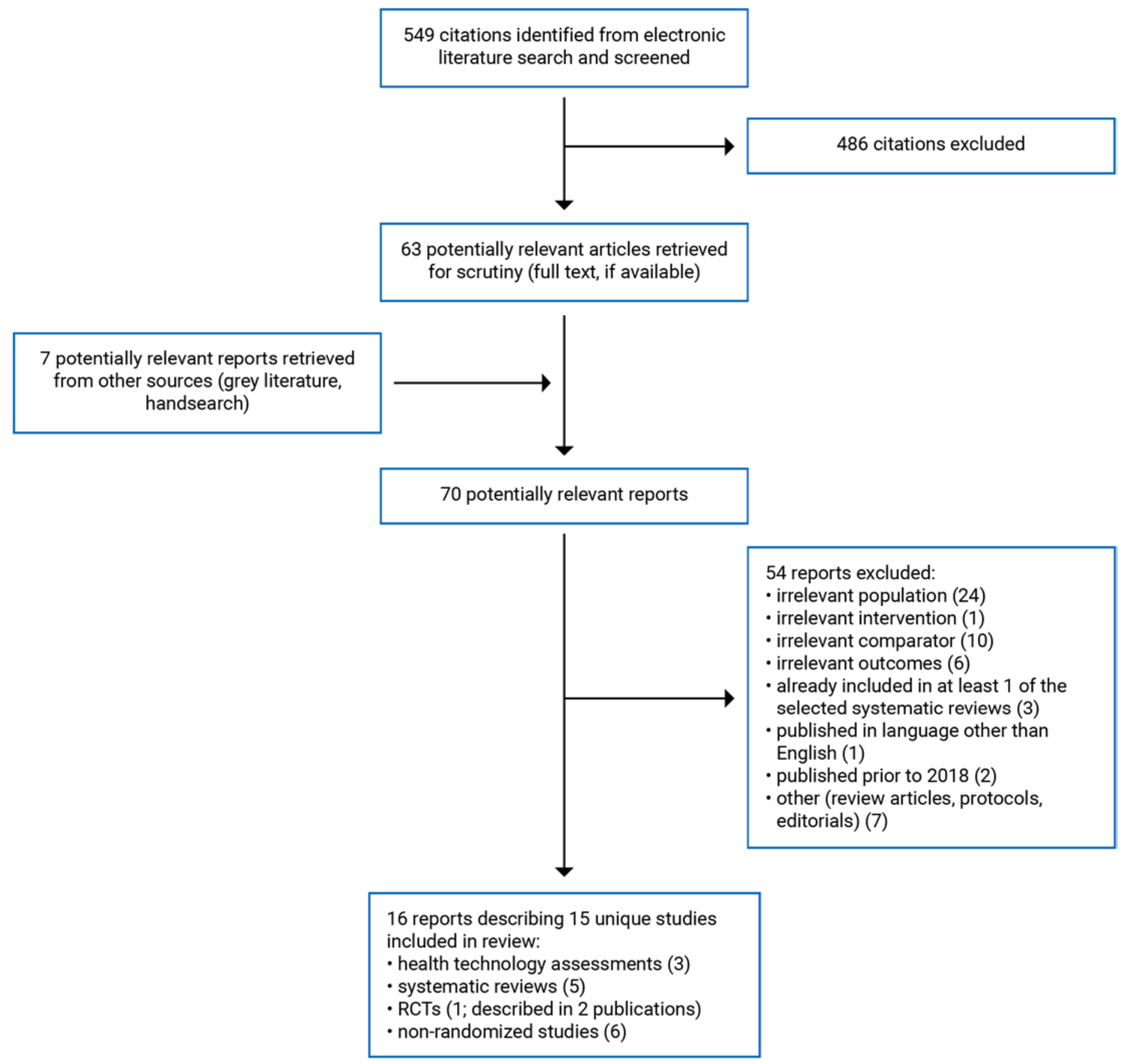




\section{Appendix 2: Characteristics of Included Publications}

\section{Table 2: Characteristics of Included Health Technology Assessments and Systematic Reviews}

\begin{tabular}{|c|c|c|c|c|}
\hline $\begin{array}{l}\text { Study citation, } \\
\text { country, funding } \\
\text { source }\end{array}$ & $\begin{array}{l}\text { Objectives, study designs, and numbers of primary } \\
\text { studies included }\end{array}$ & Population characteristics & $\begin{array}{l}\text { Intervention and } \\
\text { comparator(s) }\end{array}$ & Clinical outcomes, length of follow-up \\
\hline \multicolumn{5}{|c|}{ Health technology assessments } \\
\hline $\begin{array}{l}\text { EUnetHTA } \\
(2018)^{14} \\
\text { Participating } \\
\text { agencies were } \\
\text { from Croatia, } \\
\text { Austria, Norway, } \\
\text { Spain, Scotland, } \\
\text { Italy, Portugal, } \\
\text { and Poland } \\
\text { Funding source: } \\
\text { The European } \\
\text { Union's Health } \\
\text { Programme and } \\
\text { the European } \\
\text { Commission }\end{array}$ & $\begin{array}{l}\text { Objective: To evaluate the effectiveness and } \\
\text { safety of real-time CGM and FGM devices as } \\
\text { standalone systems for measuring glycemia in } \\
\text { people with diabetes mellitus treated with insulin. } \\
\text { Additionally, potential ethical, organization, } \\
\text { patient, and social and legal aspects were } \\
\text { investigated. } \\
\text { Study design: A systematic review and meta- } \\
\text { analysis of RCTs was conducted to address the } \\
\text { effectiveness question. In addition to these RCTs, } \\
\text { the review of safety included non-randomized } \\
\text { studies. Ethical, organization, patient, and social } \\
\text { and legal aspects were also addressed as part of } \\
\text { the HTA. } \\
\text { Number of included studies: A total of } 12 \\
\text { RCTs were included in the systematic review } \\
\text { addressing clinical effectiveness. Three additional } \\
\text { prospective non-randomized studies were } \\
\text { included to address the safety question. None of } \\
\text { these studies were relevant the current report. } \\
\text { Quality assessment tool: As part of the review of } \\
\text { clinical effectiveness, RCTs were assessed using } \\
\text { the Cochrane risk-of-bias tool. The risk of bias of } \\
\text { studies included to address the safety question } \\
\text { was not assessed. }\end{array}$ & $\begin{array}{l}\text { Studies of people, of any age } \\
\text { (e.g., adults and children) } \\
\text { with diabetes mellitus (i.e., } \\
\text { type } 1 \text {, type } 2 \text {, or gestational } \\
\text { diabetes) treated with insulin, } \\
\text { either through insulin pump } \\
\text { therapy or MDII were eligible. } \\
\text { Only primary studies of } \\
\text { children ( } \leq 18 \text { years of age) } \\
\text { were considered relevant to } \\
\text { the current report. }\end{array}$ & $\begin{array}{l}\text { Intervention: Real-time } \\
\text { CGM and FGM devices } \\
\text { (used adjunctively with } \\
\text { SMBG or non-adjunctively). } \\
\text { Only primary studies that } \\
\text { examined FGMs (i.e., } \\
\text { FreeStyle Libre devices) were } \\
\text { considered relevant to the } \\
\text { current report. } \\
\text { Comparators: SMBG devices. } \\
\text { Studies comparing real-time } \\
\text { CGM and FGM devices were } \\
\text { also considered eligible. } \\
\text { Only primary studies that } \\
\text { used SMBG techniques as } \\
\text { comparators were considered } \\
\text { relevant to the current report. }\end{array}$ & $\begin{array}{l}\text { Clinical outcomes: } \\
\text { - Measures of glucose management } \\
\text { (e.g., glucose time in range metrics, } \\
\text { hemoglobin A1C) } \\
\text { - Quality of life } \\
\text { - Patient satisfaction } \\
\text { - Fear of hypoglycemia } \\
\text { - Adverse events (e.g., rates of } \\
\text { diabetic ketoacidosis) } \\
\text { - Number of daily finger-stick tests } \\
\text { - Adherence } \\
\text { - Device accuracy (e.g., MARD scores) } \\
\text { - Length of follow-up: Varied by } \\
\text { individual study. }\end{array}$ \\
\hline
\end{tabular}


Study citation,

country, funding

source

Health

Technology

Wales (2018) ${ }^{16}$

Wales

\section{Funding}

source: Health

Technology

Wales is funded

by the Welsh

Government
Objectives, study designs, and numbers of primary studies included

Objective: To assess the clinical and cost-

effectiveness of the FreeStyle Libre FGM device

for the management of type 1 or type 2 diabetes.

Study design: A systematic review was

conducted. Eligible study designs were systematic

reviews of RCTs and any additional RCTs. A review

of cost-effectiveness studies was also conducted

but was not considered relevant to the current

report.

Number of included studies: Data from 2 RCTs

and 1 subgroup analysis of data from 1 of the

RCTs was summarized in the review. None of

these studies were relevant the current report.

Quality assessment tool: The authors of the HTA

did not conduct their own quality assessment.

Rather, the authors summarized the quality

assessment completed by the authors of

systematic reviews identified in their search.

\section{Intervention and \\ Population characteristics \\ comparator(s)}

\begin{tabular}{l|l} 
Studies of people, of any & Intervention: FGM (i.e.,
\end{tabular}

\begin{tabular}{l|l} 
age, with type 1, type 2, & FreeStyle Libre).
\end{tabular}

or gestational diabetes

mellitus were included. Only

primary studies of children

Comparators: SMBG

techniques.
Clinical outcomes, length of follow-up

Clinical outcomes:

- Hemoglobin A1C

- Glucose levels

- Hypoglycemia

- Fear of hypoglycemia

- Behaviour

- Diabetes self-care

- Diabetes-related quality of life

- Diabetes distress

- Depressive symptoms

- Patient satisfaction

- Adverse events

- Health care utilization

- Patient-reported usability

- Cost-effectiveness

- Length of follow-up: Varied by individual study. 
Study citation,

country, funding

source

Objectives, study designs, and numbers of primary studies included

Lo Scalzo et al. $(2018)^{15}$

Italy

Funding source: The project was

funded by the

Italian Ministry

of Health and

Agenas.

Objective: To determine the clinical effectiveness and safety of FGM systems for children with type 1 diabetes or adults with type 1 or type 2 diabetes requiring insulin therapy. The HTA also included an assessment of costs and patient perceptions associated with FGM systems; however, these were not considered relevant to the current report. Study design: Systematic review and metaanalysis. Eligible study designs included HTA reports, systematic reviews, and RCTs or controlled studies.

Number of included studies: A total of 2 studies were included in the systematic review regarding clinical effectiveness and safety. None of these studies were relevant the current report.

Quality assessment tool: The methodological quality of each included study was assessed using the criteria established by the Cochrane tool for assessing risk of bias.

\begin{tabular}{|c|c|c|}
\hline Population characteristics & $\begin{array}{l}\text { Intervention and } \\
\text { comparator(s) }\end{array}$ & Clinical outcomes, length of follow-up \\
\hline $\begin{array}{l}\text { Studies of children (between } \\
\text { the ages of } 4 \text { and } 18 \text { ) with } \\
\text { type } 1 \text { diabetes and studies } \\
\text { of adults with type } 1 \text { or type } \\
2 \text { diabetes requiring insulin } \\
\text { therapy were included. Only } \\
\text { primary studies of children } \\
\text { ( } \leq 18 \text { years of age) were } \\
\text { considered relevant to the } \\
\text { current report. }\end{array}$ & $\begin{array}{l}\text { Intervention: FGM systems } \\
\text { (i.e., FreeStyle Libre) } \\
\text { Comparators: Any other } \\
\text { glucose monitoring system } \\
\text { (e.g., SMBG, real-time CGM). } \\
\text { Only primary studies that } \\
\text { used SMBG techniques as } \\
\text { comparators were considered } \\
\text { relevant to the current report. }\end{array}$ & $\begin{array}{l}\text { Clinical outcomes: } \\
\text { - Hemoglobin A1C } \\
\text { - Hypoglycemic events } \\
\text { - Hospitalization due to hypo- or } \\
\text { hyperglycemia } \\
\text { - Hyperglycemia and diabetic } \\
\text { ketoacidosis } \\
\text { - Adverse events } \\
\text { - Pain or discomfort related to } \\
\text { glucose monitoring } \\
\text { - Quality of life } \\
\text { - Length of follow-up: Varied by } \\
\text { individual study. }\end{array}$ \\
\hline
\end{tabular}




\begin{tabular}{|c|c|c|c|c|}
\hline $\begin{array}{l}\text { Study citation, } \\
\text { country, funding } \\
\text { source }\end{array}$ & $\begin{array}{l}\text { Objectives, study designs, and numbers of primary } \\
\text { studies included }\end{array}$ & Population characteristics & $\begin{array}{l}\text { Intervention and } \\
\text { comparator(s) }\end{array}$ & Clinical outcomes, length of follow-up \\
\hline \multicolumn{5}{|c|}{ Systematic reviews } \\
\hline $\begin{array}{l}\text { Castellana et al. } \\
(2020)^{17} \\
\text { Italy } \\
\text { Funding source: } \\
\text { No financial } \\
\text { support was } \\
\text { received for this } \\
\text { work }\end{array}$ & $\begin{array}{l}\text { Objective: To investigate the effectiveness and } \\
\text { safety of FGM in people with type } 1 \text { or type } 2 \\
\text { diabetes. } \\
\text { Study design: Systematic review and meta- } \\
\text { analysis of RCTs and observational studies. } \\
\text { Number of included studies: A total of } 13 \\
\text { studies were included in the systematic review (2 } \\
\text { prospective cohort studies were relevant to the } \\
\text { current report). } \\
\text { Quality assessment tool: RCTs were assessed } \\
\text { using the Cochrane Collaboration's tool for } \\
\text { assessing risk of bias. Non-randomized studies } \\
\text { were assessed using the National Heart, Lung, } \\
\text { and Blood Institute Quality Assessment Tool. }\end{array}$ & $\begin{array}{l}\text { Studies of children, } \\
\text { adolescents, and adult } \\
\text { outpatients diagnosed with } \\
\text { type } 1 \text { or type } 2 \text { diabetes, } \\
\text { treated with MDII or } \\
\text { continuous subcutaneous } \\
\text { insulin infusion were } \\
\text { eligible for inclusion. Only } \\
\text { primary studies of children } \\
\text { ( } \leq 18 \text { years of age) were } \\
\text { considered relevant to the } \\
\text { current report. }\end{array}$ & $\begin{array}{l}\text { Intervention: FGM systems } \\
\text { (i.e., FreeStyle Libre). } \\
\text { Comparators: SMBG } \\
\text { techniques or no comparator. } \\
\text { Only primary studies that } \\
\text { used SMBG techniques as } \\
\text { comparators were considered } \\
\text { relevant to the current report. }\end{array}$ & $\begin{array}{l}\text { Clinical outcomes: } \\
\text { - Hemoglobin A1C } \\
\text { - Glucose time in range metrics } \\
\text { - Hypoglycemic events } \\
\text { - Number of SMBG measurements } \\
\text { - Total daily dose of insulin } \\
\text { - Patient satisfaction } \\
\text { - Adverse events } \\
\text { - Discontinuation } \\
\text { - Length of follow-up: Studies were } \\
\text { required to have a minimum follow- } \\
\text { up of } 8 \text { weeks. Follow-up periods } \\
\text { varied by individual study. }\end{array}$ \\
\hline $\begin{array}{l}\text { Cowart et al. } \\
(2020)^{18} \\
\text { US } \\
\text { Funding source: } \\
\text { No financial } \\
\text { support was } \\
\text { received for this } \\
\text { work }\end{array}$ & $\begin{array}{l}\text { Objective: To systematically review the effect of } \\
\text { FGM on measures of clinical effectiveness and } \\
\text { patient satisfaction in people with type } 1 \text { or type } 2 \\
\text { diabetes. } \\
\text { Study design: Systematic review of RCTs. } \\
\text { Number of included studies: A total of } 9 \text { RCTs } \\
\text { were included in the systematic review (1 RCT } \\
\text { was relevant to the current report). } \\
\text { Quality assessment tool: The quality of included } \\
\text { studies was assessed using the Cochrane risk-of- } \\
\text { bias tool. }\end{array}$ & $\begin{array}{l}\text { Studies of people (of any } \\
\text { age) with type } 1 \text {, type } 2 \text {, or } \\
\text { gestational diabetes were } \\
\text { eligible for inclusion. Studies } \\
\text { of hospitalized or critically ill } \\
\text { people were excluded. Only } \\
\text { primary studies of children } \\
\text { ( } \leq 18 \text { years of age) were } \\
\text { considered relevant to the } \\
\text { current report. }\end{array}$ & $\begin{array}{l}\text { Intervention: FGM systems } \\
\text { (i.e., FreeStyle Libre). } \\
\text { Comparators: Alternative } \\
\text { methods of monitoring } \\
\text { blood glucose (e.g., SMBG } \\
\text { techniques, CGM). Only } \\
\text { primary studies that used } \\
\text { SMBG techniques as } \\
\text { comparators were considered } \\
\text { relevant to the current report. }\end{array}$ & $\begin{array}{l}\text { Clinical outcomes: } \\
\text { - Hemoglobin A1C } \\
\text { - Glucose time in range metrics } \\
\text { - Hypoglycemic events } \\
\text { - Patient satisfaction } \\
\text { - Adverse events } \\
\text { - Length of follow-up: Follow-up } \\
\text { periods varied by individual study. }\end{array}$ \\
\hline
\end{tabular}


Study citation,

country, funding source

Objectives, study designs, and numbers of primary studies included

Dicembrini et al. $(2020)^{19}$

Italy

Funding source:

No financial

support was

received for this

work

Objective: To assess the effect of CGM and FGM systems on glycemic control in people with type 1 diabetes.

Study design: Systematic review and metaanalysis of RCTs.

Number of included studies: A total of 27 studies were included in the systematic review (none were relevant to the current report).
Quality assessment tool: The risk of bias of included primary studies was described and assessed according to 7

specific domains (i.e., random sequence generation, allocation concealment, blinding of participants and personnel, blinding of outcome assessment, incomplete outcome data, selective reporting, and other biases).

De Ridder et al.

$(2019)^{20}$

Belgium

Funding source:

No financial

support was

received for this

work relevant to the current report).
Objective: To evaluate the effectiveness of

novel glucose monitoring and insulin delivery

technologies for the management of type 1

diabetes.

Study design: Systematic review of RCTs.

Number of included studies: A total of 19 studies

were included in the systematic review (none were

Quality assessment tool: Included studies were assessed using a modified checklist for RCTs of the Dutch Cochrane Centre.

\section{\begin{tabular}{c|c} 
Population characteristics & $\begin{array}{c}\text { Intervention and } \\
\text { comparator(s) }\end{array}$
\end{tabular}}

Studies of people (of any age) with type 1 diabetes were eligible for inclusion. Only primary studies of children ( $\leq 18$ years of age) were considered relevant to the current report.

Studies of children and non-pregnant adults with type 1 diabetes were included. Studies specific to outcomes assessed exclusively during the nighttime were excluded Only primary studies of children ( $\leq 18$ years of age) were considered relevant to the current report.
Intervention: Real-time

CGM and FGM devices.

Only primary studies that examined FGMs (i.e., FreeStyle Libre devices) were considered relevant to the current report.

Comparators: SMBG techniques.

\section{Studies that compared FGM}

real-time CGM, sensor-

augmented pump therapy,

hybrid closed-loop insulin

delivery systems, or artificial pancreases vs. each other were eligible. Only primary studies that compared FGM vs. SMBG techniques were considered relevant to the current report.
Clinical outcomes, length of follow-up

\section{Clinical outcomes:}

- Hemoglobin A1C

- Glucose time in range metrics

- Hypoglycemic events

- Quality of life

- Treatment satisfaction

- Adverse events (e.g., ketoacidosis)

- Length of follow-up: Studies were required to have a minimum followup of 12 weeks. Follow-up periods varied by individual study.

\section{Clinical outcomes:}

- Hemoglobin A1C

- Glucose time in range metrics

- Time in hypoglycemia

- Quality of life

- Length of follow-up: Studies were required to have a minimum followup of 8 weeks. Follow-up periods varied by individual study. 
Study citation,

country, funding

source

Objectives, study designs, and numbers of primary studies included

Dicembrini et al.

$(2019)^{21}$

Italy

No financial

support was

received for this

work

Objective: To assess the effectiveness of

continuous subcutaneous insulin infusion, CGM, and FGM compared to MDII and SMBG in people with type 2 diabetes.

Study design: Systematic review and metaanalysis of RCTs. were included in the systematic review (none were
Funding source: relevant to the current report).

Quality assessment tool: The risk of bias of included primary studies was described and assessed according to 7

specific domains (i.e., random sequence generation, allocation concealment, blinding of participants and personnel, blinding of outcome assessment, incomplete outcome data, selective reporting, and other bias).
Number of included studies: A total of 12 studies

\begin{tabular}{|c|c|c|}
\hline Population characteristics & $\begin{array}{l}\text { Intervention and } \\
\text { comparator(s) }\end{array}$ & Clinical outcomes, length of follow-up \\
\hline $\begin{array}{l}\text { Studies of people, of any } \\
\text { age, with type } 2 \text { diabetes } \\
\text { were included. Only } \\
\text { primary studies of children } \\
\text { ( } \leq 18 \text { years of age) were } \\
\text { considered relevant to the } \\
\text { current report. }\end{array}$ & $\begin{array}{l}\text { Studies that compared } \\
\text { continuous subcutaneous } \\
\text { insulin infusion vs. MDII or } \\
\text { studies that compared real- } \\
\text { time CGM or FGM vs. SMBG } \\
\text { techniques were eligible } \\
\text { for inclusion. Only primary } \\
\text { studies that compared FGM } \\
\text { vs. SMBG techniques were } \\
\text { considered relevant to the } \\
\text { current report. }\end{array}$ & $\begin{array}{l}\text { Clinical outcomes: } \\
\text { - Hemoglobin A1C } \\
\text { - Quality of life } \\
\text { - Hypoglycemic events } \\
\text { - Total insulin dose } \\
\text { - Body weight } \\
\text { - Treatment satisfaction } \\
\text { - Adverse events } \\
\text { - Length of follow-up: Studies were } \\
\text { required to have a minimum follow- } \\
\text { up of } 12 \text { weeks. Follow-up periods } \\
\text { varied by individual study. }\end{array}$ \\
\hline
\end{tabular}

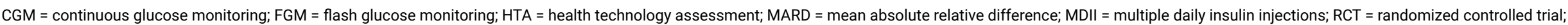
SMBG = self-monitoring blood glucose. 
Table 3: Characteristics of Included Primary Clinical Studies

\begin{tabular}{|c|c|c|c|c|}
\hline $\begin{array}{l}\text { Study citation, } \\
\text { country, funding } \\
\text { source }\end{array}$ & $\begin{array}{c}\text { Objective and study } \\
\text { design }\end{array}$ & Population characteristics & $\begin{array}{l}\text { Intervention and } \\
\text { comparator(s) }\end{array}$ & $\begin{array}{l}\text { Clinical outcomes, length of } \\
\text { follow-up }\end{array}$ \\
\hline \multicolumn{5}{|c|}{ RCTs } \\
\hline $\begin{array}{l}\text { Boucher } \\
\text { et al. }(2020)^{22} \text { and } \\
\text { Marsters et al. } \\
(2020)^{23} \\
\text { New Zealand } \\
\text { Funding source: } \\
\text { Funding was } \\
\text { received from a } \\
\text { Cure Kids grant, } \\
\text { the Australasian } \\
\text { Pediatric Endocrine } \\
\text { Group, and the } \\
\text { University of } \\
\text { Otago. }\end{array}$ & $\begin{array}{l}\text { Objective: To assess } \\
\text { the effectiveness } \\
\text { of FGM vs. SMBG } \\
\text { with respect to } \\
\text { glycemic outcomes, } \\
\text { psychosocial } \\
\text { outcomes, and } \\
\text { cutaneous adverse } \\
\text { events in youth with } \\
\text { type } 1 \text { diabetes. } \\
\text { Study design: Multi- } \\
\text { centre, open-label, } \\
\text { parallel-group RCT. }\end{array}$ & $\begin{array}{l}\text { Inclusion criteria: Youth, between the ages of } 13 \text { and } 20 \\
\text { years, with type } 1 \text { diabetes (duration of at least } 12 \text { months), } \\
\text { and mean hemoglobin A1C } \geq 9 \% \text { in the } 6 \text { months before } \\
\text { enrolment. This study was considered eligible as mean } \\
\text { participant age was below } 18 \text { years. } \\
\text { Excluded: Those with any severe diabetes-related } \\
\text { complication, other uncontrolled medical or psychiatric } \\
\text { conditions, current or previous CGM or FGM device use within } \\
4 \text { previous months, current participation in another drug or } \\
\text { device study that could affect glucose measurements, and } \\
\text { those who were pregnant. } \\
\text { Number of participants: } 64 \text { ( } 33 \text { in the FGM group; } 31 \text { in the } \\
\text { SMBG group). } \\
\text { Mean age: } 16.5 \text { (SD = } 1.9 \text { ) years in the FGM group; } 16.7 \text { (SD } \\
=2.2 \text { ) years in the SMBG group. } \\
\text { Gender: } 48 \% \text { female in the FGM group; } 48 \% \text { female in the } \\
\text { SMBG group. } \\
\text { Mean BMI (z score): } 0.67 \text { (SD = } 1.05 \text { ) in the FGM group; } 0.73 \\
\text { (SD = 0.96) in the SMBG group. } \\
\text { Mean baseline hemoglobin A1C: } 10.8 \% \text { (SD = } 1.7 \% \text { ) in the } \\
\text { FGM group; } 11.2 \%(S D=1.6 \% \text { in the SMBG group. }\end{array}$ & $\begin{array}{l}\text { Intervention: FGM using } \\
\text { the FreeStyle Libre } \\
\text { system. Participants also } \\
\text { received education on } \\
\text { using the system. } \\
\text { Comparators: SMBG with } \\
\text { a glucometer. }\end{array}$ & $\begin{array}{l}\text { Clinical outcomes: } \\
\text { - Hemoglobin A1C } \\
\text { - Glucose monitoring frequency } \\
\text { - Quality of life (measured with } \\
\text { the PedsQL) } \\
\text { - Fear of hypoglycemia } \\
\text { (measured with the HFS-II) } \\
\text { - Diabetes treatment } \\
\text { satisfaction (measured with } \\
\text { the DTSQ) } \\
\text { - Adverse events (e.g., } \\
\text { cutaneous problems, severe } \\
\text { hypoglycemia, diabetic } \\
\text { ketoacidosis) } \\
\text { - Hypoglycemic events } \\
\text { - Treatment satisfaction } \\
\text { - Follow-up: } 6 \text { months }\end{array}$ \\
\hline
\end{tabular}




\begin{tabular}{|c|c|c|c|c|}
\hline $\begin{array}{l}\text { Study citation, } \\
\text { country, funding } \\
\text { source }\end{array}$ & $\begin{array}{c}\text { Objective and study } \\
\text { design }\end{array}$ & Population characteristics & $\begin{array}{l}\text { Intervention and } \\
\text { comparator(s) }\end{array}$ & $\begin{array}{l}\text { Clinical outcomes, length of } \\
\text { follow-up }\end{array}$ \\
\hline \multicolumn{5}{|c|}{ Non-randomized studies } \\
\hline $\begin{array}{l}\text { Al Hakey et al. } \\
(2020)^{24} \\
\text { Saudi Arabia } \\
\text { Funding source: } \\
\text { No funding was } \\
\text { received for this } \\
\text { study. }\end{array}$ & $\begin{array}{l}\text { Objective: To evaluate } \\
\text { the effect of FGM } \\
\text { on diabetes distress } \\
\text { in children and } \\
\text { adolescents with type } 1 \\
\text { diabetes. } \\
\text { Study design: Single- } \\
\text { centre, single-arm, } \\
\text { prospective cohort } \\
\text { study. Participants } \\
\text { were selected using a } \\
\text { convenience sample. }\end{array}$ & $\begin{array}{l}\text { Inclusion criteria: Children and adolescents, between the } \\
\text { ages of } 13 \text { and } 19 \text { years, with type } 1 \text { diabetes who used the } \\
\text { conventional finger-pricking method to self-test their glucose } \\
\text { level. Participants were on insulin therapy for at least } 6 \\
\text { months before enrolment. This study was considered eligible } \\
\text { as mean participant age was below } 18 \text { years. } \\
\text { Excluded: Those with dermatological disorders or alterations } \\
\text { at the sensor application site, severe or unstable medical } \\
\text { conditions, severe hypoglycemia necessitating third- } \\
\text { party assistance, diabetic ketoacidosis, hyperosmolar } \\
\text { hyperglycemic state, and those who were pregnant. } \\
\text { Number of participants: } 187 \text {. } \\
\text { Mean age: } 15.3 \text { (SD = NR) years. } \\
\text { Gender: } 56.7 \% \text { female. } \\
\text { BMI: } 44.9 \% \text { of participants had a BMI } \geq 25 \mathrm{~kg} / \mathrm{m}^{2} \text {. } \\
\text { Mean baseline hemoglobin A1C: } 8.2 \% \text { (SD = } 2.3 \%) \text {. }\end{array}$ & $\begin{array}{l}\text { Intervention: FGM using } \\
\text { the FreeStyle Libre } \\
\text { system. } \\
\text { Comparators: This study } \\
\text { did not include a control } \\
\text { group; however, within- } \\
\text { group comparisons were } \\
\text { made from before to after } \\
\text { switching to FGM and all } \\
\text { participants were } \\
\text { using SMBG using the } \\
\text { conventional finger-prick } \\
\text { method at baseline. }\end{array}$ & $\begin{array}{l}\text { Clinical outcomes: } \\
\text { - Hemoglobin A1C } \\
\text { - Glucose monitoring frequency } \\
\text { - Hypoglycemic events } \\
\text { - Diabetes-related distress } \\
\text { (measured with the 28-item } \\
\text { T1-Diabetes Distress Scale) } \\
\text { - Adverse events } \\
\text { - Follow-up: } 12 \text { weeks. }\end{array}$ \\
\hline
\end{tabular}




\begin{tabular}{|c|c|c|c|c|}
\hline $\begin{array}{l}\text { Study citation, } \\
\text { country, funding } \\
\text { source }\end{array}$ & $\begin{array}{c}\text { Objective and study } \\
\text { design }\end{array}$ & Population characteristics & $\begin{array}{l}\text { Intervention and } \\
\text { comparator(s) }\end{array}$ & $\begin{array}{c}\text { Clinical outcomes, length of } \\
\text { follow-up }\end{array}$ \\
\hline $\begin{array}{l}\text { Charleer et al. } \\
(2020)^{25} \\
\text { Belgium } \\
\text { Funding source: } \\
\text { A doctoral grant } \\
\text { for strategic basic } \\
\text { research and a } \\
\text { PhD fellowship } \\
\text { from Fonds } \\
\text { Wetenschappelijk } \\
\text { Onderzoek. }\end{array}$ & $\begin{array}{l}\text { Objective: To assess } \\
\text { the effectiveness of } \\
\text { FGM with respect to } \\
\text { glycemic control and } \\
\text { quality of life in youth } \\
\text { with type } 1 \text { diabetes. } \\
\text { Study design: Single- } \\
\text { centre, single-arm, } \\
\text { prospective cohort } \\
\text { study. }\end{array}$ & $\begin{array}{l}\text { Inclusion criteria: Youth with type } 1 \text { diabetes (duration of at } \\
\text { least } 3 \text { months). } \\
\text { Excluded: Children < } 4 \text { years of age were excluded. } \\
\text { Number of participants: } 138 \text {. } \\
\text { Mean age: } 12.9(\mathrm{SD}=3.1) \text { years. } \\
\text { Gender: } 54.3 \% \text { female. } \\
\text { Mean BMI: } 19.8(\mathrm{SD}=3.5) \mathrm{kg} / \mathrm{m}^{2} . \\
\text { Mean baseline hemoglobin } \mathrm{A} 1 \mathrm{C}: 7.2 \%(\mathrm{SD}=1.1 \%)\end{array}$ & $\begin{array}{l}\text { Intervention: FGM using } \\
\text { the FreeStyle Libre } \\
\text { system. } \\
\text { Comparators: This study } \\
\text { did not include a control } \\
\text { group; however, within- } \\
\text { group comparisons were } \\
\text { made from before to after } \\
\text { switching to FGM and all } \\
\text { participants appeared } \\
\text { to be using SMBG at } \\
\text { baseline. }\end{array}$ & $\begin{array}{l}\text { Clinical outcomes: } \\
\text { - Quality of life } \\
\text { - Acute diabetes complications } \\
\text { (e.g., hypoglycemia, } \\
\text { ketoacidosis) } \\
\text { - School or work absenteeism } \\
\text { - Hemoglobin A1C } \\
\text { - Total daily dose of insulin } \\
\text { - BMI } \\
\text { - Reasons for discontinuing } \\
\text { FGM } \\
\text { - Monitoring complications } \\
\text { - Follow-up: } 24 \text { months. }\end{array}$ \\
\hline $\begin{array}{l}\text { Lim et al. }(2020)^{26} \\
\text { Singapore } \\
\text { Funding source: A } \\
\text { KK Women's and } \\
\text { Children's Hospital } \\
\text { Health Fund grant }\end{array}$ & $\begin{array}{l}\text { Objective: To } \\
\text { evaluate the clinical } \\
\text { effectiveness of FGM in } \\
\text { adolescents with type } 1 \\
\text { diabetes. } \\
\text { Study design: Single- } \\
\text { centre, single-arm, } \\
\text { prospective cohort } \\
\text { study. Participants } \\
\text { were selected using a } \\
\text { convenience sample. }\end{array}$ & $\begin{array}{l}\text { Inclusion criteria: Adolescents, between the ages of } 13 \text { and } 18 \\
\text { years, with type } 1 \text { diabetes and on a basal-bolus MDII regimen } \\
\text { with a hemoglobin A1C > } 8.5 \% \text {. } \\
\text { Excluded: No specific exclusion criteria were listed. } \\
\text { Number of participants: } 30 \text { ( } 22 \text { in the completers group; } 8 \text { in } \\
\text { the non-completers group). } \\
\text { Mean age: } 15.3(\mathrm{SD}=1.6 \text { ) years in the completers group; } 15.5 \\
(\mathrm{SD}=1.6) \text { years in the non-completers group. } \\
\text { Gender: } 66.7 \% \text { female. } \\
\text { Mean BMI: NR. } \\
\text { Mean baseline hemoglobin A1C: } 10.3 \% \text { (SD }=2.0 \%) \text { in the } \\
\text { completers group; } 9.2 \%(S D=1.25 \%) \text { in the non-completers } \\
\text { group. }\end{array}$ & $\begin{array}{l}\text { Intervention: FGM using } \\
\text { the FreeStyle Libre } \\
\text { system. } \\
\text { Comparators: This study } \\
\text { did not include a control } \\
\text { group; however, within- } \\
\text { group comparisons were } \\
\text { made from before to after } \\
\text { switching to FGM and all } \\
\text { participants appeared } \\
\text { to be using SMBG at } \\
\text { baseline. }\end{array}$ & $\begin{array}{l}\text { Clinical outcomes: } \\
\text { - Self efficacy (measures with } \\
\text { CIDS survey scores) } \\
\text { - Glucose time in range metrics } \\
\text { - Hypoglycemic events } \\
\text { - Glucose levels } \\
\text { - Sensor scanning frequency } \\
\text { - Follow-up: } 4 \text { weeks. }\end{array}$ \\
\hline
\end{tabular}




\begin{tabular}{|c|c|c|c|c|}
\hline $\begin{array}{l}\text { Study citation, } \\
\text { country, funding } \\
\text { source }\end{array}$ & $\begin{array}{l}\text { Objective and study } \\
\text { design }\end{array}$ & Population characteristics & $\begin{array}{l}\text { Intervention and } \\
\text { comparator(s) }\end{array}$ & $\begin{array}{l}\text { Clinical outcomes, length of } \\
\text { follow-up }\end{array}$ \\
\hline $\begin{array}{l}\text { Al Hakey et al. } \\
(2019)^{27} \\
\text { Saudi Arabia } \\
\text { Funding source: } \\
\text { No funding was } \\
\text { received for this } \\
\text { study. Abbot } \\
\text { Diabetes Care } \\
\text { provided financial } \\
\text { assistance for } \\
\text { writing assistance } \\
\text { and paid for article } \\
\text { processing } \\
\text { Charges. }\end{array}$ & $\begin{array}{l}\text { Objective: To } \\
\text { investigate mental } \\
\text { well-being and } \\
\text { treatment satisfaction } \\
\text { in a pediatric and young } \\
\text { adult population with } \\
\text { type } 1 \text { diabetes who } \\
\text { used FGM. } \\
\text { Study design: Single- } \\
\text { centre, single-arm, } \\
\text { prospective cohort } \\
\text { study. }\end{array}$ & $\begin{array}{l}\text { Inclusion criteria: Youth, between the ages of } 14 \text { and } 21 \\
\text { years, with type } 1 \text { diabetes no previous FGM experience, and } \\
\text { who had received insulin treatment via MDII or insulin pump } \\
\text { for at least the } 6 \text { months before recruitment. This study was } \\
\text { considered eligible as mean participant age was below } 18 \\
\text { years. } \\
\text { Excluded: Those who had used another interstitial glucose } \\
\text { monitoring system concurrently or } 6 \text { months before study } \\
\text { entry, those with a dermatological disorder or change at } \\
\text { the site of sensor application within } 6 \text { months, those with } \\
\text { severe or unstable medical conditions, those with severe } \\
\text { hypoglycemia requiring third-party assistance, those } \\
\text { with diabetic ketoacidosis, and those in a hyperosmolar } \\
\text { hyperglycemic state. } \\
\text { Number of participants: } 33 \text {. } \\
\text { Mean age: } 15.9 \text { (SD = 1.7) years. } \\
\text { Gender: } 54.5 \% \text { female. } \\
\text { Mean BMI: } 22.3(\mathrm{SD}=2.5) \mathrm{kg} / \mathrm{m}^{2} . \\
\text { Mean baseline hemoglobin A1C: } 8.8 \% \text { (SD = 1.4\%). }\end{array}$ & $\begin{array}{l}\text { Intervention: FGM using } \\
\text { the FreeStyle Libre } \\
\text { system. } \\
\text { Comparators: This study } \\
\text { did not include a control } \\
\text { group; however, within- } \\
\text { group comparisons were } \\
\text { made from before to after } \\
\text { switching to FGM and all } \\
\text { participants were } \\
\text { using SMBG using the } \\
\text { conventional finger-prick } \\
\text { method at baseline. }\end{array}$ & $\begin{array}{l}\text { Clinical outcomes: } \\
\text { - Diabetes treatment } \\
\text { satisfaction (measured with } \\
\text { the DTSQ) } \\
\text { - Well-being (measured with } \\
\text { WHO-5 Well-Being Index) } \\
\text { - Follow-up: } 12 \text { weeks. }\end{array}$ \\
\hline $\begin{array}{l}\text { Deeb et al. (2019) } \\
\text { United Arab } \\
\text { Emirates } \\
\text { Funding source: } \\
\text { NR. }\end{array}$ & $\begin{array}{l}\text { Objective: To assess } \\
\text { the impact of FGM on } \\
\text { detecting hypoglycemia } \\
\text { and on adherence to } \\
\text { glucose monitoring } \\
\text { in children and } \\
\text { adolescents with type } 1 \\
\text { diabetes. } \\
\text { Study design: Single- } \\
\text { centre, single-arm, } \\
\text { prospective cohort } \\
\text { study. }\end{array}$ & $\begin{array}{l}\text { Inclusion criteria: Children and adolescents with type } 1 \\
\text { diabetes. This study was considered eligible as mean } \\
\text { participant age was below } 18 \text { years. } \\
\text { Excluded: No specific exclusion criteria were listed. } \\
\text { Number of participants: } 75 \text {. } \\
\text { Mean age: } 11.9 \text { (range = } 2 \text { to } 19 \text { ) years. } \\
\text { Gender: } 62.7 \% \text { female. } \\
\text { Mean BMI: NR. } \\
\text { Mean baseline hemoglobin A1C: } 8.2 \% \text { (range }=5.9 \% \text { to } \\
10.2 \% \text { ). }\end{array}$ & $\begin{array}{l}\text { Intervention: FGM using } \\
\text { the FreeStyle Libre } \\
\text { system. } \\
\text { Comparators: This study } \\
\text { did not include a control } \\
\text { group; however, within- } \\
\text { group comparisons were } \\
\text { made from before to after } \\
\text { switching from SMBG } \\
\text { using a glucometer to } \\
\text { FGM. }\end{array}$ & $\begin{array}{l}\text { Clinical outcomes: } \\
\text { - Glucose monitoring frequency } \\
\text { - Hypoglycemic events } \\
\text { - Duration of hypoglycemia } \\
\text { - Follow-up: Varied by individual } \\
\text { participant but was between } 2 \\
\text { to } 4 \text { weeks. }\end{array}$ \\
\hline
\end{tabular}




\begin{tabular}{|c|c|c|c|c|}
\hline $\begin{array}{l}\text { Study citation, } \\
\text { country, funding } \\
\text { source }\end{array}$ & $\begin{array}{l}\text { Objective and study } \\
\text { design }\end{array}$ & Population characteristics & $\begin{array}{l}\text { Intervention and } \\
\text { comparator(s) }\end{array}$ & $\begin{array}{l}\text { Clinical outcomes, length of } \\
\text { follow-up }\end{array}$ \\
\hline $\begin{array}{l}\text { Pintus et al. } \\
(2019)^{29} \\
\text { UK } \\
\text { Funding source: } \\
\text { NR. }\end{array}$ & $\begin{array}{l}\text { Objective: To assess } \\
\text { the effectiveness of } \\
\text { FGM in children with } \\
\text { type } 1 \text { diabetes with } \\
\text { respect to metabolic } \\
\text { outcomes and quality } \\
\text { of life. } \\
\text { Study design: Single- } \\
\text { centre, single-arm, } \\
\text { prospective cohort } \\
\text { study. }\end{array}$ & $\begin{array}{l}\text { Inclusion criteria: Children, between the ages of } 5 \text { and } 18 \\
\text { years, with type } 1 \text { diabetes. } \\
\text { Excluded: Those who were less than } 5 \text { years of age, those on } \\
\text { CGM, and those with unstable medical conditions. } \\
\text { Number of participants: } 52 \text {. } \\
\text { Mean age: } 11.6(\mathrm{SD}=3.6) \text { years. } \\
\text { Gender: } 33.5 \% \text { female. } \\
\text { Mean BMI: NR. } \\
\text { Mean baseline hemoglobin A1C: NR }\end{array}$ & $\begin{array}{l}\text { Intervention: FGM using } \\
\text { the FreeStyle Libre } \\
\text { system. } \\
\text { Comparators: This study } \\
\text { did not include a control } \\
\text { group; however, within- } \\
\text { group comparisons were } \\
\text { made from before to after } \\
\text { switching to FGM and all } \\
\text { participants appeared } \\
\text { to be using SMBG at } \\
\text { baseline. }\end{array}$ & $\begin{array}{l}\text { Clinical outcomes: } \\
\text { - Hemoglobin A1C } \\
\text { - Quality of life (measured with } \\
\text { the PedsQL) } \\
\text { - Follow-up: } 12 \text { months. }\end{array}$ \\
\hline
\end{tabular}

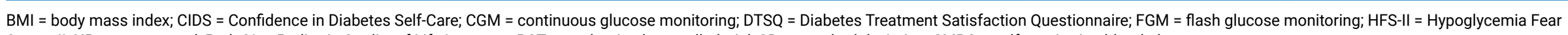
Survey-ll; NR = not reported; PedsQL = Pediatric Quality of Life Inventory; RCT = randomized controlled trial; SD = standard deviation; SMBG = self-monitoring blood glucose. 


\section{Appendix 3: Critical Appraisal of Included Publications}

\section{Table 4: Strengths and Limitations of Systematic Reviews Using AMSTAR $2^{12}$}

\begin{tabular}{|c|c|}
\hline Strengths & Limitations \\
\hline \multicolumn{2}{|c|}{ Castellana et al. (2020) ${ }^{17}$} \\
\hline $\begin{array}{l}\text { - The objectives and inclusion criteria were clearly stated and } \\
\text { included components of population, intervention, comparator, } \\
\text { and outcomes } \\
\text { - The review methods were established before conducting the } \\
\text { review - Multiple databases were searched (i.e., PubMed, } \\
\text { CENTRAL, Scopus, and Web of Science). Additionally, } \\
\text { reference lists of included studies were examined } \\
\text { - Key search terms and search restrictions were provided (e.g., } \\
\text { there were no language restrictions) } \\
\text { - A flow chart of study selection was provided } \\
\text { - Article selection, data extraction, and quality assessment } \\
\text { were conducted by } 2 \text { independent reviewers } \\
\text { - The review authors described the included relevant primary } \\
\text { studies in adequate detail } \\
\text { - The risk of bias of included primary studies was assessed } \\
\text { using satisfactory techniques (i.e., the Cochrane } \\
\text { Collaboration's tool for assessing risk of bias was used for } \\
\text { RCTs; the National Heart, Lung, and Blood Institute Quality } \\
\text { Assessment Tool was used for observational studies) } \\
\text { - Review authors reported on sources of funding for the } \\
\text { included primary studies } \\
\text { - Appropriate methods for the statistical combination of results } \\
\text { were used in the network meta-analyses } \\
\text { - Heterogeneity was assessed by the I2 test } \\
\text { - Publication bias was assessed with Egger's test (none was } \\
\text { detected, except for change in hemoglobin A1C from baseline } \\
\text { to the last available follow-up on FGM) } \\
\text { - The review authors declared their potential conflicts of } \\
\text { interest (authors had competing interests with Eli Lilly, Novo } \\
\text { Rordisk, Sanofi Aventis, AstraZeneca, Bruno Farmaceutici, } \\
\text { Italy, LifeScan, and Movi) } \\
\text { - Sounding were disclosed (there was no funding } \\
\text { review) }\end{array}$ & $\begin{array}{l}\text { - The authors did not provide justification for their selection of } \\
\text { eligible study designs } \\
\text { - A grey literature search was not completed } \\
\text { - A list of studies excluded after full-text review was not } \\
\text { provided (although the reasons for exclusion were) } \\
\text { - The potential impact of risk of bias in primary studies on the } \\
\text { results of the meta-analyses were not examined } \\
\text { - There was limited consideration for the risk of bias in primary } \\
\text { studies when interpreting and discussing the results of the } \\
\text { review } \\
\text { - The authors did not examine or discuss the impact of } \\
\text { heterogeneity on the results of the review in detail }\end{array}$ \\
\hline
\end{tabular}




\section{Cowart et al. (2020) ${ }^{18}$}

- The objectives and inclusion criteria were clearly stated and included components of population, intervention, comparator, and outcomes

- Multiple databases were searched (i.e., Embase, PubMed, and the Cochrane Library CENTRAL Register of Controlled Trials). Key search terms and search restrictions were provided (e.g., studies published up to November 8, 2019 were eligible)

- A flow chart of study selection was provided

- Study selection was conducted by 2 independent researchers (disagreements were resolved by a third researcher)

- The review authors described the included relevant primary studies in adequate detail

- The risk of bias of included primary studies was assessed using a satisfactory technique (i.e., the Cochrane risk-of-bias tool)

- Review authors stated that they had no conflicts of interest related to this review

- Sources of funding were disclosed (there was no funding received for this review)
- It was unclear whether the review methods were established before conducting the review (no mention of a protocol)

- The authors did not provide justification for their selection of eligible study designs

- A grey literature search was not completed

- It was unclear if data extraction and quality assessment were conducted in duplicate

- A list of studies excluded after full-text review was not provided (although the reasons for exclusion were)

- Review authors did not report on sources of funding for the included primary studies (although primary study funding source was considered in risk of bias assessments)

- There was limited consideration for the risk of bias in primary studies when interpreting and discussing the results of the review

- The authors did not examine or discuss the impact of heterogeneity on the results of the review in detail

Dicembrini et al. (2020) $)^{19}$

- The objectives and inclusion criteria were clearly stated and included components of population, intervention, comparator, and outcomes

- The review methods were established before conducting the review

- Multiple databases were searched (i.e., MEDLINE and Embase). Additionally, reference lists of included studies and clinical trials registries (i.e., clinicaltrials.gov, WHO International Clinical Trials Registry Platform, and EU Clinical Trials Register were examined). Additionally, reference lists of included studies and previous meta-analyses were examined. A clinical trial registry (i.e., clinicaltrials.gov) was also screened for ongoing trials

- Key search terms and search restrictions were provided (e.g., studies published up to July 31, 2019 were eligible)

- A flow chart of study selection was provided

- Data extraction was conducted by 2 independent researchers (disagreements were resolved by a third researcher)

- Review authors stated that they had no conflicts of interest related to this review

- Sources of funding were disclosed (there was no funding received for this review)
- The authors did not provide justification for their selection of eligible study designs

- A grey literature search was not completed

- It was unclear if study selection and quality assessment were conducted in duplicate

- A list of studies excluded after full-text review was not provided (although the reasons for exclusion were) 
De Ridder et al. (2019) ${ }^{20}$

- The objectives and inclusion criteria were clearly stated and included components of population, intervention, comparator, and outcomes

- Multiple databases were searched (i.e., MEDLINE and the Cochrane Central Register of Controlled Trials)

- Key search terms and search restrictions were provided (e.g., only studies published in English were eligible, the search was restricted to the past 5 years up to May 30, 2019)

- A flow chart of study selection was provided

- Study selection was conducted by 2 independent researchers (disagreements were resolved by a third researcher)

- The review authors declared their potential conflicts of interest (1 author was a consultant for Abbott, A. Menarini Diagnostics, Lilly, Medtronic, Novo Nordisk, and Roche Diagnostics)

- Sources of funding were disclosed (there was no funding received for this review)
- It was unclear whether the review methods were established before conducting the review (no mention of a protocol)

- The authors did not provide justification for their selection of eligible study designs

- A grey literature search was not completed

- It was unclear if data extraction and quality assessment were conducted in duplicate

- A list of studies excluded after full-text review was not provided (although the reasons for exclusion were)

\section{Dicembrini et al. (2019) ${ }^{21}$}

- The objectives and inclusion criteria were clearly stated and included components of population, intervention, comparator, and outcomes

- The review methods were established before conducting the review

- In addition to the electronic search, reference lists of included studies and previous meta-analyses were examined. A clinical trial registry (i.e., clinicaltrials.gov) was also screened for ongoing trials

- Key search terms and search restrictions were provided (e.g., no language or date restrictions were imposed)

- A flow chart of study selection was provided

- Data extraction was conducted by 2 independent researchers (disagreements were resolved by a third researcher)

- Sources of funding were disclosed (there was no funding received for this review)
- The authors did not provide justification for their selection of eligible study designs

- The literature search was conducted in 1 database (i.e., MEDLINE)

- A grey literature search was not completed

- It was unclear if study selection and quality assessment were conducted in duplicate

- A list of studies excluded after full-text review was not provided (although the reasons for exclusion were)

- Review authors did not disclose any potential conflicts of interest related to this review 


\section{EUnetHTA (2018) $)^{14}$}

- The objectives and inclusion criteria were clearly stated and included components of population, intervention, comparator, and outcomes

- The review methods were established before conducting the review

- Multiple databases were searched (i.e., the Cochrane Central Register of Controlled Trials, The Database of Abstracts of Reviews of Effects, The Health Technology Assessment Database, NHS Economic Evaluation Database, MEDLINE, Embase, EBSCO CINAHL). Additionally, reference lists of included studies and clinical trials registries (i.e., clinicaltrials. gov, WHO International Clinical Trials Registry Platform, and EU Clinical Trials Register) were examined

- Key search terms and search restrictions were provided (e.g., only studies published in English were eligible)

- Study selection and quality assessment were conducted by 2 independent researchers

- A flow chart of study selection was provided

- Data extraction was conducted by 1 researcher using a standardized data extraction form and was verified by a second researcher for completeness and accuracy (disagreements were resolved through discussion to reach a consensus, involving a third researcher if necessary)

- Review authors stated that they had no conflicts of interest related to this review

- Sources of funding were disclosed (the European Union's Health Programme and the European Commission) and were unlikely to have had an effect on the findings of the review
- The authors did not provide justification for their selection of eligible study designs

- A grey literature search was not completed

- A list of studies excluded after full-text review was not provided (although the reasons for exclusion were)

\section{Health Technology Wales (2018) ${ }^{16}$}

- The objectives and inclusion criteria were clearly stated and included components of population, intervention, comparator, and outcomes

- Search restrictions were provided (e.g., only studies published in English were eligible, the search was restricted between May 2013 and May 2018)

- A flow chart of study selection was provided

- Sources of funding were disclosed (the Welsh Government) and were unlikely to have had an effect on the findings of the review
- It was unclear whether the review methods were established before conducting the review (no mention of a protocol)

- The authors did not provide justification for their selection of eligible study designs

- Key search terms were not provided

- Databases used to identify relevant studies were not described

- A grey literature search was not completed

- It was unclear if study selection and data extraction were conducted in duplicate

- The authors of the HTA did not conduct their own quality assessment

- A list of studies excluded after full-text review was not provided (although the reasons for exclusion were)

- Review authors did not disclose any potential conflicts of interest related to this review 


\section{Lo Scalzo et al. (2018) ${ }^{15}$}

- The objectives and inclusion criteria were clearly stated and included components of population, intervention, comparator, and outcomes

- Multiple databases were searched (i.e., PubMed, Embase, and the Cochrane Library)

- Key search terms and search restrictions were provided

- A flow chart of study selection was provided

- A list of studies excluded after full-text review, with their reasons for exclusion, was provided

- The review authors declared their potential conflicts of interest ( 1 author had congress expenses paid for by Medtronic Italia and Novo Nordisk; 1 author had worked for Sanofi Aventis and Merck and had attended conferences organized by Abbott; 1 author participated in congresses sponsored by Abbott; 1 author had been a consultant for the Lombardy Region, Asl of Biella, Action Group A1/B3, AOU of Udine and participated in Mundipharma organized meetings)

- Sources of funding were disclosed (the Italian Ministry of Health and Agenas) and were unlikely to have had an effect on the findings of the review
- It was unclear whether the review methods were established before conducting the review (no mention of a protocol)

- The authors did not provide justification for their selection of eligible study designs

- A grey literature search was not completed

- It was unclear if study selection, data extraction, and quality assessment were conducted in duplicate

AMSTAR 2 = A MeaSurement Tool to Assess systematic Reviews 2; FGM = flash glucose monitor; HTA = health technology assessment; RCT = randomized controlled trial . 


\section{Table 5: Strengths and Limitations of Clinical Studies Using the Downs and Black checklist ${ }^{13}$}

\begin{tabular}{|c|c|}
\hline Strengths & Limitations \\
\hline \multicolumn{2}{|c|}{ RCTs } \\
\hline \multicolumn{2}{|c|}{ Boucher et al. $(2020)^{22}$ and Marsters et al. $(2020)^{23}$} \\
\hline $\begin{array}{l}\text { - The objectives, intervention, comparator, and main outcomes } \\
\text { were clearly described } \\
\text { - Participant eligibility criteria were provided } \\
\text { - Participant characteristics (e.g., age, sex or gender, BMI, } \\
\text { baseline hemoglobin A1C) were clearly described } \\
\text { - The main findings of the study were clearly described } \\
\text { - Estimates of random variability (e.g., standard deviations, } \\
\text { confidence intervals) and actual P values were reported } \\
\text { - All important adverse events that may have been a } \\
\text { consequence of the intervention were recorded } \\
\text { - No participants were lost to follow-up } \\
\text { - Study participants, care providers, and setting appeared to be } \\
\text { representative of the population and care setting of interest } \\
\text { - Length of follow-up was consistent between intervention and } \\
\text { control groups } \\
\text { - Compliance with the intervention was reliable } \\
\text { - Outcome measures were valid } \\
\text { - The authors declared that they had no potential conflicts of } \\
\text { interest } \\
\text { - Sources of funding were disclosed (a Cure Kids grant, the } \\
\text { Australasian Pediatric Endocrine Group, and the University of } \\
\text { Otago) and were unlikely to have had an effect on the findings } \\
\text { of the study }\end{array}$ & $\begin{array}{l}\text { - This was an open-label study with no blinding of study } \\
\text { participants or outcome assessors (although statistical } \\
\text { analyses were performed by a biostatistician blinded to group } \\
\text { allocation) } \\
\text { - This study was conducted across } 3 \text { academic diabetes cents } \\
\text { in New Zealand; the generalizability to Canadian settings was } \\
\text { unclear }\end{array}$ \\
\hline
\end{tabular}


Al Hakey et al. $(2020)^{24}$

- The objectives, intervention, comparator, and main outcomes were clearly described

- Participant eligibility criteria were provided

- Participant characteristics (e.g., age, sex or gender, BMI, baseline hemoglobin A1C) were clearly described

- The main findings of the study were clearly described

- Estimates of random variability (e.g., standard deviations, confidence intervals) and actual $P$ values were reported

- No participants were lost to follow-up

- Care providers and setting appeared to be representative of those of interest

- Compliance with the intervention was reliable

- Outcome measures were valid

- The authors declared that they had no potential conflicts of interest

- Sources of funding were disclosed (there was no funding received for this study)
- The study reported within-group comparisons from before to after switching from SMBG to FGM; there were no between-group comparisons (i.e., comparisons between a group of participants who used FGM and a control group of participants who used SMBG); therefore, the results are susceptible to numerous forms of bias that threaten both internal and external validity. Any outcomes observed in participants should not be attributed to FGM alone, as there are many uncontrolled factors that may have contributed to the findings of this study

- It was unclear if all important adverse events that may have been a consequence of the intervention were recorded

- Participants were recruited using a convenience sample and may not be fully representative of the population they were recruited from

- This was an open-label study with no blinding of study participants or outcome assessors

- Single-centre study (conducted in Saudi Arabia); the generalizability to Canadian settings was unclear

Charleer et al. (2020) ${ }^{25}$

- The objectives, intervention, and main outcomes were clearly described

- Participant eligibility criteria were provided

- Participant characteristics (e.g., age, sex or gender, BMI, baseline hemoglobin A1C) were clearly described

- The main findings of the study were clearly described

- Estimates of random variability (e.g., standard deviations, confidence intervals) were reported

- adverse events that may have been a consequence of the intervention were recorded

- Number and characteristics of participants lost to follow-up were described

- Study participants, care providers, and setting appeared to be representative of the population and care setting of interest

- Compliance with the intervention was reliable

- Outcome measures were valid

- The authors declared their potential conflicts of interest (the authors had many financial and non-financial conflicts of interest with industry, including holding advisory positions and having received support for travel or previous research)

- Sources of funding were disclosed (a doctoral grant for strategic basic research and a PhD fellowship from Fonds Wetenschappelijk Onderzoek) and were unlikely to have had an effect on the findings of the study
- While all participants were assumed to have used SMBG before starting FGM, this was not explicitly stated by study authors

- The study reported within-group comparisons from before to after switching from SMBG to FGM; there were no between-group comparisons (i.e., comparisons between a group of participants who used FGM and a control group of participants who used SMBG); therefore, the results are susceptible to numerous forms of bias that threaten both internal and external validity. Any outcomes observed in participants should not be attributed to FGM alone, as there are many uncontrolled factors that may have contributed to the findings of this study

- A substantial proportion of study participants (i.e., 31.1\%) had missing data for the primary outcome at 24-month follow-up

- Actual P values were not reported for some outcomes

- This was an open-label study with no blinding of study participants or outcome assessors

- Single-centre study (conducted in Belgium); the generalizability to Canadian settings was unclear 
Lim et al. $(2020)^{26}$

- The objectives, intervention, and main outcomes were clearly described

- Participant eligibility criteria were provided

- Participant characteristics (e.g., age, sex or gender, baseline hemoglobin A1C) were clearly described

- The main findings of the study were clearly described

- Estimates of random variability (e.g., standard deviations, confidence intervals) and actual $P$ values were reported

- All important adverse events that may have been a consequence of the intervention were recorded

- Number and characteristics of participants lost to follow-up were described

- Care providers and setting appeared to be representative of those of interest

- Compliance with the intervention was reliable

- Outcome measures were valid

- The authors declared that they had no potential conflicts of interest

- Sources of funding were disclosed (a KK Women's and Children's Hospital Health Fund grant) and were unlikely to have had an effect on the findings of the study

\section{Al Hakey et al. (2019) $)^{27}$}

- The objectives, intervention, comparator, and main outcomes were clearly described

- Participant eligibility criteria were provided

- Participant characteristics (e.g., age, sex or gender, BMI, baseline hemoglobin A1C) were clearly described

- The main findings of the study were clearly described

- Estimates of random variability (e.g., standard deviations, confidence intervals) and actual $P$ values were reported

- No participants were lost to follow-up

- Study participants, care providers, and setting appeared to be representative of the population and care setting of interest

- Compliance with the intervention was reliable

- Outcome measures were valid

- The authors declared that they had no potential conflicts of interest

- Sources of funding were disclosed (Abbott Diabetes care provided financial assistance for medical writing assistance and paid for article processing fees, but did not provide any funding for conducting the study) and were unlikely to have had an effect on the findings of the study
- While all participants were assumed to have used SMBG before starting FGM, this was not explicitly stated by study authors

- The study reported within-group comparisons from before to after switching from SMBG to FGM; there were no between-group comparisons (i.e., comparisons between a group of participants who used FGM and a control group of participants who used SMBG); therefore, the results are susceptible to numerous forms of bias that threaten both internal and external validity. Any outcomes observed in participants should not be attributed to FGM alone, as there are many uncontrolled factors that may have contributed to the findings of this study

- Participants were recruited using a convenience sample and may not be fully representative of the population they were recruited from

- This was an open-label study with no blinding of study participants or outcome assessors

- Single-centre study (conducted in Singapore); the generalizability to Canadian settings was unclear
- The study reported within-group comparisons from before to after switching from SMBG to FGM; there were no between-group comparisons (i.e., comparisons between a group of participants who used FGM and a control group of participants who used SMBG); therefore, the results are susceptible to numerous forms of bias that threaten both internal and external validity. Any outcomes observed in participants should not be attributed to FGM alone, as there are many uncontrolled factors that may have contributed to the findings of this study

- It was unclear if all important adverse events that may have been a consequence of the intervention were recorded

- This was an open-label study with no blinding of study participants or outcome assessors

- Single-centre study (conducted in Saudi Arabia); the generalizability to Canadian settings was unclear 
Deeb et al. (2019) 28

- The objectives, intervention, comparator, and main outcomes were clearly described

- Participant eligibility criteria were provided

- Participant characteristics (e.g., age, sex or gender, baseline hemoglobin A1C) were clearly described

- The main findings of the study were clearly described

- Number and characteristics of participants lost to follow-up were described

- Study participants, care providers, and setting appeared to be representative of the population and care setting of interest

- Compliance with the intervention was reliable

- Outcome measures were valid

- The authors declared that they had no potential conflicts of interest
- The study reported within-group comparisons from before to after switching from SMBG to FGM; there were no between-group comparisons (i.e., comparisons between a group of participants who used FGM and a control group of participants who used SMBG); therefore, the results are susceptible to numerous forms of bias that threaten both internal and external validity. Any outcomes observed in participants should not be attributed to FGM alone, as there are many uncontrolled factors that may have contributed to the findings of this study

- Estimates of random variability (e.g., standard deviations, confidence intervals) and actual $P$ values were not reported

- It was unclear if all important adverse events that may have been a consequence of the intervention were recorded

- This was an open-label study with no blinding of study participants or outcome assessors

- The sources of funding for the study were not disclosed

- Single-centre study (conducted in the United Arab Emirates); the generalizability to Canadian settings was unclear

Pintus et al. (2019) ${ }^{29}$

- The objectives, intervention, and main outcomes were clearly described

- Participant eligibility criteria were provided

- Participant characteristics (e.g., age, sex, or gender) were clearly described

- The main findings of the study were clearly described

- Estimates of random variability (e.g., standard deviations, confidence intervals) and actual $P$ values were reported

- The number of participants lost to follow-up was described

- Study participants, care providers, and setting appeared to be representative of the population and care setting of interest

- Compliance with the intervention was reliable

- Outcome measures were valid
- While all participants were assumed to have used SMBG before starting FGM, this was not explicitly stated by study authors

- The study reported within-group comparisons from before to after switching from SMBG to FGM; there were no between-group comparisons (i.e., comparisons between a group of participants who used FGM and a control group of participants who used SMBG); therefore, the results are susceptible to numerous forms of bias that threaten both internal and external validity. Any outcomes observed in participants should not be attributed to FGM alone, as there are many uncontrolled factors that may have contributed to the findings of this study

- It was unclear if all important adverse events that may have been a consequence of the intervention were recorded

- A substantial proportion of study participants (i.e., 42\%) were unable to complete the study due to the financial costs associated with the FGM system. Data from these participants were not available for the analysis

- This was an open-label study with no blinding of study participants or outcome assessors

- The authors did not disclose any potential conflicts of interest

- The sources of funding for the study were not disclosed

- Single-centre study (conducted in the UK); the generalizability to Canadian settings was unclear

$\mathrm{BMI}=$ body mass index; FGM = flash glucose monitoring; $\mathrm{SMBG}$ = self-monitoring blood glucose. 


\section{Appendix 4: Main Study Findings and Authors' Conclusions}

\section{Summary of Findings Included Systematic Reviews}

\section{Castellana et al. (2020) ${ }^{17}$}

Main Study Findings

Systematic review and meta-analysis of RCTs and observational studies regarding the clinical effectiveness and safety of FGM in people with type 1 or type 2 diabetes.

Relevant primary studies: The systematic review included 13 RCTs and observational studies that measured the clinical effectiveness or safety of FGM systems; however, only primary studies that compared FGM versus SMBG in pediatric populations were relevant to the current report (2 prospective cohort studies). Although the systematic review included metaanalyses, there was no meta-analysis specific to the primary studies relevant to the current report. Therefore, relevant results were summarized individually by primary study.

Summary of relevant findings from the systematic review:

\section{- Hemoglobin A1C}

- Campbell et al. (2018)

- Change in mean hemoglobin A1C from baseline (patients were using SMBG) to final follow-up

- After FGM (N = NR): $7.5 \%(S D=0.9 \%)$

- Prior to FGM (N = NR): $7.9 \%(\mathrm{SD}=1.0 \%)$

- Mean difference: $-0.40 \%$ (95\% Cl, $-0.70 \%$ to $-0.10 \%)$

- Messaaoui et al. (2019)

- Difference in mean change in hemoglobin A1C from baseline to final follow-up in patients on FGM versus patients on SMBG

- FGM group ( $N=N R): 0.03 \%(S D=1.71 \%)$

- $\operatorname{SMBG}$ group ( $\mathrm{N}=\mathrm{NR}): 0.19 \%(\mathrm{SD}=1.91 \%)$

- Mean difference: $-0.16 \%(95 \% \mathrm{Cl},-0.17 \%$ to $0.38 \%)$

- Change in mean hemoglobin A1C from baseline (patients were using SMBG) to final follow-up

- After FGM (N = NR): $7.66 \%(S D=1.19 \%)$

- Prior to FGM (N = NR): $7.63 \%(S D=1.24 \%)$

- Mean difference: $-0.03 \%(95 \% \mathrm{Cl},-0.17 \%$ to $0.23 \%)$

\section{- Glucose time in range metrics}

- Campbell et al. (2018)

- Change in mean time with a glucose value between 3.9 and $10.0 \mathrm{mmol} / \mathrm{L}$ (70 and $180 \mathrm{mg} / \mathrm{dL}$ ) from baseline (patients were using SMBG) to final follow-up

- After FGM (N = NR): $11.1(\mathrm{SD}=3.3$ ) hours per day

- Prior to FGM (N = NR): $10.1(\mathrm{SD}=3.0)$ hours per day

- Mean difference: 1.00 ( $95 \% \mathrm{Cl},-0.01$ to 2.01 ) hours per day 
- Change in mean time with a glucose value greater than $10.0 \mathrm{mmol} / \mathrm{L}$ (> $180 \mathrm{mg} / \mathrm{dL}$ ) from baseline (patients were using SMBG) to final follow-up

- After FGM (N = NR): $11.6(S D=3.9)$ hours per day

- Prior to FGM (N = NR): $12.7(\mathrm{SD}=3.5)$ hours per day

- Mean difference: - 1.10 (95\% Cl, -2.29 to 0.09) hours per day

- Change in mean time with a glucose value less than $3.9 \mathrm{mmol} / \mathrm{L}(<70 \mathrm{mg} / \mathrm{dL})$ from baseline (patients were using SMBG) to final follow-up

- After FGM (N = NR): $1.4(\mathrm{SD}=1.2)$ hours per day

- Prior to FGM (N = NR): $1.1(\mathrm{SD}=1.2)$ hours per day

- Mean difference: -0.30 (95\% Cl, -0.08 to 0.62$)$ hours per day

- Messaaoui et al. (2019)

- Change in mean time with a glucose value less than $3.9 \mathrm{mmol} / \mathrm{L}(<70 \mathrm{mg} / \mathrm{dL})$ from baseline (patients were using SMBG) to final follow-up

- After FGM (N = NR): $3.6(S D=1.92)$ hours/day

- Prior to FGM (N = NR): 4.32 (SD = 1.68) hours/day

- Mean difference: $-0.72(95 \% \mathrm{Cl},-1.02$ to -0.42$)$ hours/day

\section{- Frequency of glucose monitoring}

- Campbell et al. (2018)

- Change in the mean number of SMBG measurements per day from baseline (patients were using SMBG) to final follow-up

- After FGM (N = NR): $1.6(\mathrm{SD}=1.9)$ measurements per day

- Prior to FGM (N = NR): $7.7(\mathrm{SD}=2.5)$ measurements per day

- Mean difference: $-6.10(95 \% \mathrm{Cl},-6.81$ to -5.39$)$ measurements per day

- Messaaoui et al. (2019)

- Difference in mean change in the number of SMBG measurements per day from baseline to final follow-up in patients on FGM versus patients on SMBG

- FGM group ( $\mathrm{N}=\mathrm{NR}):-4.5(\mathrm{SD}=2.12)$ measurements per day

- SMBG group ( $N=\mathrm{NR}): 0.0(\mathrm{SD}=2.79)$ measurements per day

- Mean difference: $-4.5(95 \% \mathrm{Cl},-5.27$ to -3.73$)$ measurements per day

\section{- Total daily insulin dose}

- Campbell et al. (2018)

- Change in the mean total daily insulin dose from baseline (patients were using SMBG) to final follow-up

- After FGM ( $N=N R): 37.2(S D=25.5)$ insulin units per day

- Prior to FGM (N = NR): 35.8 (SD = 25.6) insulin units per day

- Mean difference: 1.40 (95\% Cl, -7.00 to 9.80) insulin units per day

- Patient satisfaction

- Campbell et al. (2018)

- Change in mean DTSQ (teen version) mean scores from baseline (patients were using SMBG) to final follow-up 
- The authors of the systematic review noted that there were statistically significant improvements; however, mean values before and after FGM were not described in the review

- Change in DTSQ (parent version) mean scores from baseline (patients were using SMBG) to final follow-up

- The authors of the systematic review noted that there were statistically significant improvements; however, mean values before and after FGM were not described in the review

\section{- Adverse events}

- Campbell et al. (2018)

- Change in the mean number of hypoglycemic events per day from baseline (patients were using SMBG) to final follow-up

- After FGM (N = NR): $1.0(\mathrm{SD}=0.7)$ per day

- Prior to FGM (N = NR): $0.8(\mathrm{SD}=0.7)$ per day

- Mean difference: $0.20(95 \% \mathrm{Cl},-0.02$ to 0.42$)$ per day

\section{Author's Conclusion}

"A limited number of studies on FGM are reported in the literature, using different study designs, including patients with different characteristics at baseline, and with a heterogeneous reporting. Particularly, we believe that the general lack of a specific training in patients on FGM represented the most relevant finding of our systematic review. Acknowledging these limitations, FGM proved to be a reliable option to achieve a significant reduction in hemoglobin $\mathrm{A} 1 \mathrm{C}$ and time below $70 \mathrm{mg} / \mathrm{dL}$ in uncontrolled patients with type 1 or type 2 diabetes or other insulin-dependent diabetes on prandial insulin only, MDII or continuous subcutaneous insulin infusion. When compared with SMBG, FGM was associated with a similar change in hemoglobin A1C, a lower number of SMBG measurements, and a reduced risk of discontinuation. FGM should thus be regarded as an effective intervention to be proposed to properly selected patients, as a part of a multicomponent strategy. Further studies on the comparison between SMBG and trained FGM are however needed (p. 9)."17

\section{Cowart et al. (2020) ${ }^{18}$ \\ Main Study Findings}

Systematic review of RCTs that assessed the clinical effectiveness of FGM in people with type 1 or type 2 diabetes.

Relevant primary studies: The systematic review included a total of 9 RCTs that assessed the clinical effectiveness of FGM systems; however, only primary studies that compared FGM versus SMBG in pediatric populations were relevant to the current report (1 RCT). Findings from the primary study relevant to the current report were extracted and summarized.

Summary of relevant findings from the systematic review:

\section{- Glucose time in range metrics}

o Piona et al. (2018)

- Mean proportion of time with a glucose value between 3.9 and $10.0 \mathrm{mmol} / \mathrm{L}$ (70 and $180 \mathrm{mg} / \mathrm{dL})$

- FGM group ( $N=25): 50.9 \%(S D=11.3 \%)$ 
- $\operatorname{SMBG}$ group $(\mathrm{N}=20): 50.8 \%(\mathrm{SD}=13.8 \%)$

- $P=0.64$

- Mean proportion of time with a glucose value greater than $10.0 \mathrm{mmol} / \mathrm{L}$

(> $180 \mathrm{mg} / \mathrm{dL})$

- FGM group ( $N=25): 45.2 \%(S D=N R)$

- $\operatorname{SMBG}$ group $(\mathrm{N}=20): 44.7 \%(\mathrm{SD}=\mathrm{NR})$

- $P=0.69$

- Mean proportion of time with a glucose value less than $3.0 \mathrm{mmol} / \mathrm{L}(<54 \mathrm{mg} / \mathrm{dL}$ )

- FGM group $(N=25): 1.3 \%(S D=N R)$

- $\operatorname{SMBG}$ group $(\mathrm{N}=20): 1.4 \%(\mathrm{SD}=\mathrm{NR})$

- $P=0.98$

- Adverse events

o Piona et al. (2018)

- "No severe hypoglycemic events or serious adverse events occurred (p. 341)."18

\section{Author's Conclusion}

"Although hemoglobin A1C and SMBG are current standard of care for assessing glycemic control in patients with type 1 diabetes mellitus and type 2 diabetes mellitus, these glycemic measures lack incorporation of detailed metrics such as glycemic variability and time in glycemic range and time spent in hypoglycemia. An advantage to using [FGM] is the ability to assess these glycemic measures, although available evidence is mixed regarding improvements in these glycemic measures with [FGM] use. In this systematic review, RCT evidence suggests a benefit on lowering hemoglobin A1C in select populations with diabetes, such as those $<65$ years of age with uncontrolled type 1 diabetes mellitus or type 2 diabetes mellitus, and those using MDII or continuous subcutaneous insulin infusion. [FGM] has been associated with high patient satisfaction and lower diabetes distress with [FGM] use compared with usual care. The clinical application of these findings should be viewed in the context of the patient population under investigation in the RCT trials and account for those who may be most likely to benefit from [FGM] use (p.343)."18

\section{RCTs}

\section{Boucher et al. (2020) $)^{22}$ and Marsters et al. (2020) ${ }^{23}$ Main Study Findings}

Multi-centre, open-label, parallel-group RCT that assessed glycemic outcomes, psychosocial outcomes, and cutaneous adverse events experienced by youth with type 1 diabetes who monitored glucose levels using FGM with the FreeStyle Libre $(\mathrm{N}=33)$ or SMBG $(\mathrm{N}=31)$.

Summary of relevant findings:

\section{- Hemoglobin A1C}

- Change in mean hemoglobin $\mathrm{A} 1 \mathrm{C}$ throughout the 6-month follow-up period

- FGM group at baseline $(\mathrm{N}=33): 10.8 \%(\mathrm{SD}=1.7 \%)$

- FGM group at 6 months $(\mathrm{N}=33): 10.0 \%(\mathrm{SD}=1.5 \%)$

- SMBG group at baseline ( $N=31): 11.2 \%(S D=1.6 \%)$

- $S M B G$ group at 6 months $(N=31): 10.7 \%(S D=1.5 \%)$ 
- Difference in adjusted changes at 6 months: $-0.2 \%(95 \% \mathrm{Cl},-0.9 \%$ to $0.5 \%)$

. $P=0.576$

\section{- Frequency of glucose monitoring}

- Change in frequency of glucose checks (interstitial and capillary) per day throughout the 6-month follow-up period

- FGM group at baseline $(\mathrm{N}=33): 1.8(\mathrm{SD}=1.6)$ checks per day

- FGM group at 6 months $(N=33): 3.8(S D=3.1)$ checks per day

- SMBG group at baseline $(\mathrm{N}=31): 1.9(\mathrm{SD}=3.6)$ checks per day

- SMBG group at 6 months $(N=31): 1.4(S D=3.0)$ checks per day

- Difference in adjusted changes at 6 months: $2.8(95 \% \mathrm{Cl}, 1.72$ to 4.65$)$ checks per day

- $\mathrm{P}=<0.001$

\section{- Quality of life}

- Change in mean PedsQL Generic scores throughout the 6-month follow-up period

- FGM group at baseline $(\mathrm{N}=33): 73.8(\mathrm{SD}=14.0)$

- FGM group at 6 months $(\mathrm{N}=32): 77.5(\mathrm{SD}=15.7)$

- SMBG group at baseline $(\mathrm{N}=31): 75.2(\mathrm{SD}=11.9)$

- SMBG group at 6 months $(\mathrm{N}=31): 79.7(\mathrm{SD}=11.6)$

- Difference in changes at 6 months: $-1.2(95 \% \mathrm{Cl},-6.5$ to 4.1$)$

- $\mathrm{P}:=0.661$

- Change in mean PedsQL Diabetes (diabetes subscale) scores throughout the 6-month follow-up period

- FGM group at baseline $(\mathrm{N}=33): 56.9(\mathrm{SD}=16.2)$

- FGM group at 6 months $(\mathrm{N}=32): 56.5(\mathrm{SD}=17.7)$

- SMBG group at baseline ( $N=31): 57.2(S D=18.3)$

- SMBG group at 6 months $(N=31): 65.7(S D=16.7)$

- Difference in changes at 6 months: $-9.2(95 \% \mathrm{Cl},-15.2$ to -3.3$)$

- $P=0.002$

- Change in mean PedsQL Diabetes (treatment I subscale) scores throughout the 6-month follow-up period

- FGM group at baseline $(\mathrm{N}=33): 57.4(\mathrm{SD}=20.2)$

- FGM group at 6 months $(N=32): 68.9(S D=21.3)$

- SMBG group at baseline $(\mathrm{N}=31): 65.9(\mathrm{SD}=20.7)$

- SMBG group at 6 months $(\mathrm{N}=31): 68.5(\mathrm{SD}=17.9)$

- Difference in changes at 6 months: $8.1(95 \% \mathrm{Cl},-0.1$ to 16.4$)$

- $P=0.053$

- Change in mean PedsQL Diabetes (treatment II subscale) scores throughout the 6-month follow-up period

- FGM group at baseline $(\mathrm{N}=33): 67.2(\mathrm{SD}=18.6)$

- FGM group at 6 months $(\mathrm{N}=32): 74.4(\mathrm{SD}=17.3)$

- SMBG group at baseline $(\mathrm{N}=31): 68.2(\mathrm{SD}=19.5)$ 
- SMBG group at 6 months $(\mathrm{N}=31): 70.0(\mathrm{SD}=21.6)$

- Difference in changes at 6 months: $4.8(95 \% \mathrm{Cl},-2.6$ to 12.3$)$

- $P=0.204$

- Change in mean PedsQL Diabetes (worry subscale) scores throughout the 6-month follow-up period

- FGM group at baseline ( $\mathrm{N}=33): 61.6(\mathrm{SD}=22.2)$

- FGM group at 6 months $(\mathrm{N}=32): 71.6(\mathrm{SD}=23.4)$

- SMBG group at baseline $(N=31): 67.7(S D=21.5)$

- SMBG group at 6 months $(\mathrm{N}=31): 69.6(\mathrm{SD}=21.6)$

- Difference in changes at 6 months: $7.7(95 \% \mathrm{Cl},-2.3$ to 17.8$)$

- $P=0.130$

- Change in mean PedsQL Diabetes (communication subscale) scores throughout the 6-month follow-up period

- FGM group at baseline ( $N=33): 64.9(S D=28.2)$

- FGM group at 6 months $(N=32): 68.2(S D=30.5)$

- SMBG group at baseline $(\mathrm{N}=31): 70.2(\mathrm{SD}=22.3)$

- SMBG group at 6 months $(\mathrm{N}=31): 77.4(\mathrm{SD}=24.2)$

- Difference in changes at 6 months: $-5.2(95 \% \mathrm{Cl},-16.7$ to 6.2$)$

- $\mathrm{P}=0.370$

- Change in mean total PedsQL Diabetes scores throughout the 6-month follow-up period

- FGM group at baseline $(\mathrm{N}=33): 60.9(\mathrm{SD}=14.6)$

- FGM group at 6 months $(\mathrm{N}=32): 65.7(\mathrm{SD}=15.9)$

- SMBG group at baseline $(N=31): 63.7(S D=15.6)$

- SMBG group at 6 months $(\mathrm{N}=31): 68.9(\mathrm{SD}=15.1)$

- Difference in changes at 6 months: $-1.1(95 \% \mathrm{Cl},-6.2$ to 4.1$)$

- $P=0.688$

\section{- Fear of hypoglycemia}

- Change in mean HFS behaviour subscale scores throughout the 6-month follow-up period

- FGM group at baseline ( $\mathrm{N}=33): 1.75(\mathrm{SD}=0.58)$

- FGM group at 6 months $(\mathrm{N}=32): 1.70(\mathrm{SD}=0.67)$

- SMBG group at baseline $(N=31): 1.91(S D=0.63)$

- SMBG group at 6 months $(\mathrm{N}=31): 1.69(\mathrm{SD}=0.47)$

- Difference in changes at 6 months: $0.18(95 \% \mathrm{Cl},-0.08$ to 0.44$)$

- $\mathrm{P}=0.182$

- Change in mean HFS worry subscale scores throughout the 6-month follow-up period

- FGM group at baseline $(\mathrm{N}=33): 1.19(\mathrm{SD}=0.59)$

- FGM group at 6 months $(\mathrm{N}=32): 0.94(\mathrm{SD}=0.55)$

- SMBG group at baseline $(\mathrm{N}=31): 1.26(\mathrm{SD}=0.73)$

- SMBG group at 6 months $(\mathrm{N}=31): 1.14(\mathrm{SD}=0.75)$

- Difference in changes at 6 months: $-0.13(95 \% \mathrm{Cl},-0.37$ to 0.11$)$ 
- $\mathrm{P}=0.302$

\section{- Patient satisfaction}

- Change in mean item DTSQ scores throughout the 6-month follow-up period

- FGM group at baseline ( $\mathrm{N}=33): 3.96(\mathrm{SD}=0.88)$

- FGM group at 6 months $(N=32): 4.33(S D=1.12)$

- SMBG group at baseline $(N=31): 4.36(S D=0.90)$

- SMBG group at 6 months $(\mathrm{N}=31): 4.28(\mathrm{SD}=1.02)$

- Difference in changes at 6 months: $0.47(95 \% \mathrm{Cl}, 0.00$ to 0.93$)$

- $\mathrm{P}=0.048$

\section{- Adverse events}

- Proportion of participants who experienced at least 1 episode of diabetic ketoacidosis throughout the 6-month follow-up period

- FGM group ( $\mathrm{N}=33): 18 \%$

- $\operatorname{SMBG}$ group $(\mathrm{N}=31): 16 \%$

- $\mathrm{P}=$ non-significant

- Proportion of participants who experienced severe hypoglycemic events throughout the 6-month follow-up period

- FGM group ( $\mathrm{N}=33): 0 \%$

- SMBG group ( $\mathrm{N}=31): 0 \%$

- $\mathrm{P}=$ non-significant

- Number of participants who were hospitalized for reasons not attributable to participation in the study throughout the 6-month follow-up period

- FGM group $(\mathrm{N}=33): 5$

- $\operatorname{SMBG}$ group $(\mathrm{N}=31): 6$

- $\mathrm{P}=\mathrm{NR}$

- Number of FGM-associated or SMBG-associated cutaneous adverse events throughout the 6-month follow-up period

- FGM group ( $N=33): 40$

- SMBG group $(N=31): 40$

- $\mathrm{P}=0.96$

- Proportion of participants who experienced FGM-associated or SMBG-associated cutaneous adverse events throughout the 6-month follow-up period

- FGM group ( $\mathrm{N}=33): 58 \%$

- SMBG group ( $\mathrm{N}=31): 23 \%$

- $\mathrm{P}=0.004$

- Average number of symptoms reported per cutaneous adverse event

- FGM group $(\mathrm{N}=33): 2.1$

- SMBG group ( $N=31): 2.3$

- $P=0.69$

- "There was no significant difference between groups for the frequency of cutaneous adverse event reports that were rated mild, moderate or severe $(P=1.00)(p .1520) .{ }^{\prime 23}$ 


\section{Authors' Conclusion}

"In summary, this RCT in adolescents and young adults with high-risk glycemic control reveals that [FGM] does engage this complex population, as evidenced by increased glucose-monitoring behaviour and diabetes satisfaction. However, in this study, this did not translate to a statistically significant greater improvement in glycemic control over usual care with SMBG at 6 months. Ongoing efforts to find likely combined technology and psychosocial strategies to help this population are required (p.2394)."22

In conclusion, use of the FreeStyle Libre FGM system results in frequently experienced cutaneous adverse events which are reported at a similar rate to SMBG-associated cutaneous adverse events. Discontinuation over a 6 -month period due to cutaneous adverse events appears rare, with the majority of cutaneous adverse events rated as mild. While sensor loss is common among youth in this study population, this did not relate to cutaneous adverse events. Awareness of these cutaneous issues and ongoing efforts to mitigate cutaneous complications may improve the overall experience of FGM (p.1522)."23

\section{Non-randomized studies}

\section{Al Hakey et al. (2020) ${ }^{24}$}

\section{Main Study Findings}

Single-centre, single-arm, prospective cohort study that evaluated the effect of FGM on diabetes distress in children and adolescents (between the ages of 13 and 19) with type 1 diabetes $(N=187)$. Before switching to FGM, participants were monitoring their glucose levels using SMBG.

Summary of relevant findings:

\section{- Hemoglobin A1C}

- Mean hemoglobin A1C before and after the 12-week study period

- Baseline ( $N=187): 8.2 \%(S D=2.3 \%)$

- After 12 weeks of FGM ( $=187): 7.9 \%(S D=2.1 \%)$

- $P=N R$

\section{- Frequency of glucose monitoring}

- Frequency of glucose checks per day before and after the 12-week study period

- Baseline ( $N=187): 2.1(S D=1.2)$ checks per day

- After 12 weeks of FGM ( $N=187): 6.7(S D=1.7)$ checks per day

- $P=N R$

\section{- Diabetes distress}

- Mean T1-DDS (powerlessness subdomain) scores before and after the 12-week study period

- Baseline ( $N=187)$ : 3.26 (SD was presented in a figure; exact value could not be ascertained)

- After 12 weeks of FGM ( $N=187): 2.78$ (SD was presented in a figure; exact value could not be ascertained)

- $\mathrm{P}=0.001$

- Mean T1-DDS (management distress subdomain) scores before and after the 12-week study period 
- Baseline ( $N=187): 2.91$ (SD was presented in a figure; exact value could not be ascertained)

- After 12 weeks of FGM ( $N=187): 2.61$ (SD was presented in a figure; exact value could not be ascertained)

- $\mathrm{P}=0.001$

- Mean T1-DDS (hypoglycemia distress subdomain) scores before and after the 12-week study period

- Baseline ( $N=187$ ): 2.80 (SD was presented in a figure; exact value could not be ascertained)

- After 12 weeks of FGM ( $N=187)$ : 2.38 (SD was presented in a figure; exact value could not be ascertained)

- $\mathrm{P}=0.001$

- Mean T1-DDS (negative social perceptions subdomain) scores before and after the 12-week study period

- Baseline ( $N=187): 2.72$ (SD was presented in a figure; exact value could not be ascertained)

- After 12 weeks of FGM ( $N$ = 187): 2.31 (SD was presented in a figure; exact value could not be ascertained)

- $P=0.001$

- Mean T1-DDS (eating distress subdomain) scores before and after the 12-week study period

- Baseline ( $N=187): 3.56$ (SD was presented in a figure; exact value could not be ascertained)

- After 12 weeks of FGM ( $N=187): 2.67$ (SD was presented in a figure; exact value could not be ascertained)

- $P=0.001$

- Mean T1-DDS (physician distress subdomain) scores before and after the 12-week study period

- Baseline ( $N=187): 2.44$ (SD was presented in a figure; exact value could not be ascertained)

- After 12 weeks of FGM ( $N=187): 2.16$ (SD was presented in a figure; exact value could not be ascertained)

- $P=0.001$

- Mean T1-DDS (friend or family distress subdomain) scores before and after the 12-week study period

- Baseline ( $N=187)$ : 2.83 (SD was presented in a figure; exact value could not be ascertained)

- After 12 weeks of FGM ( $N$ = 187): 2.30 (SD was presented in a figure; exact value could not be ascertained)

- $P=0.001$

- Mean T1-DDS (total) scores before and after the 12-week study period

- Baseline ( $N=187$ ): 2.93 (SD was presented in a figure; exact value could not be ascertained) 
- After 12 weeks of FGM ( $N=187): 2.46$ (SD was presented in a figure; exact value could not be ascertained)

- $P=0.001$

\section{- Adverse events}

- Number of hypoglycemic events per month before and after the 12-week study period

- Baseline ( $N=187): 6.3(S D=1.7)$ events per month

- After 12 weeks of FGM $(N=187): 4.7(S D=1.9)$ events per month

- $\mathrm{P}=\mathrm{NR}$

\section{Authors' Conclusion}

"Despite the limitations of the present study, we have obtained valuable data on diabetesrelated distress among type 1 diabetes patients in Saudi Arabia. In conclusion, the results of this prospective study clearly demonstrate that the DDS subdomain scores were reduced after initiation of the FGM system scanning to determine the blood glucose levels. However, further studies are necessary to ascertain if the FGM system after prolonged and consistent use will provide enhanced results (p. 935)."${ }^{\prime 24}$

\section{Charleer et al. $(2020)^{25}$}

\section{Main Study Findings}

Single-centre, single-arm, prospective cohort study tat investigated the effectiveness of FGM with respect to glycemic control and quality of life in youth $(N=138)$ with type 1 diabetes. Before switching to FGM, participants were assumed to have been monitoring their glucose levels using SMBG.

Summary of relevant findings:

\section{- Quality of life}

- Mean DQOLY (satisfaction subscale) scores throughout the 24-month follow-up period

- Baseline ( $\mathrm{N}=120): 68.8(95 \% \mathrm{Cl}, 67.4$ to 70.3$)$

- After 6 months of FGM ( $N=103): 71.9(95 \% \mathrm{Cl}, 70.3$ to 73.4$)$

- $\mathrm{P}$ (versus baseline $)=<0.001$

- After 12 months of FGM ( $\mathrm{N}=96): 71.2(95 \% \mathrm{Cl}, 69.8$ to 72.7$)$

- $\mathrm{P}$ (versus baseline $)=<0.001$

- After 24 months of FGM ( $\mathrm{N}=84): 70.2(95 \% \mathrm{Cl}, 68.8$ to 71.5$)$

- $P($ versus baseline $)=0.055$

- Mean DQOLY (impact subscale) scores throughout the 24-month follow-up period

- Baseline ( $\mathrm{N}=120): 52.1$ (95\% Cl, 50.1 to 54.0$)$

- After 6 months of FGM ( $\mathrm{N}=103): 50.5(95 \% \mathrm{Cl}, 48.8$ to 52.1$)$

- $P$ value (versus baseline) $=<0.05$

- After 12 months of FGM ( $N=96): 50.8$ (95\% Cl, 49.0 to 52.7)

- $\mathrm{P}($ versus baseline $)=$ non-significant

- After 24 months of FGM ( $N=84): 50.3(95 \% \mathrm{Cl}, 48.4$ to 52.1)

- $\mathrm{P}($ versus baseline $)=$ non-significant

- Mean DQOLY (worry subscale) scores throughout the 24-month follow-up period 
- Baseline ( $\mathrm{N}=120): 18.8(95 \% \mathrm{Cl}, 17.6$ to 20.0$)$

- After 6 months of FGM ( $N=103): 18.4$ (95\% Cl, 17.1 to 19.7)

- $\mathrm{P}($ versus baseline $)=$ non-significant

- After 12 months of FGM ( $\mathrm{N}=96)$ : 18.6 (95\% Cl, 17.4 to 19.8)

- $P($ versus baseline $)=$ non-significant

- After 24 months of FGM ( $N=84): 18.1$ ( $95 \% \mathrm{Cl}, 17.0$ to 19.2)

- $\mathrm{P}($ versus baseline $)=$ non-significant

\section{- Fear of hypoglycemia}

- Mean HFS for children (behaviour subscale) scores throughout the 24-month follow-up period

- Baseline ( $\mathrm{N}=120): 16.1(95 \% \mathrm{Cl}, 15.1$ to 17.2$)$

- After 6 months of FGM ( $N=103): 16.4$ (95\% Cl, 15.3 to 17.4$)$

- $\mathrm{P}($ versus baseline $)=$ non-significant

- After 12 months of FGM ( $\mathrm{N}=96): 16.4(95 \% \mathrm{Cl}, 15.4$ to 17.4$)$

- $\mathrm{P}($ versus baseline $)=$ non-significant

- After 24 months of FGM ( $N=84): 17.0$ (95\% Cl, 15.9 to 18.2)

- $\mathrm{P}($ versus baseline $)=$ non-significant

- Mean HFS for children (worry subscale) scores throughout the 24-month follow-up period

- Baseline ( $N=120): 14.7$ (95\% Cl, 13.2 to 16.1)

- After 6 months of FGM ( $\mathrm{N}=103): 14.7(95 \% \mathrm{Cl}, 13.1$ to 16.3$)$

- $\mathrm{P}($ versus baseline $)=$ non-significant

- After 12 months of FGM ( $\mathrm{N}=96): 13.5(95 \% \mathrm{Cl}, 12.2$ to 14.8$)$

- $\mathrm{P}($ versus baseline $)=$ non-significant

- After 24 months of FGM ( $N=84): 14.1$ (95\% Cl, 12.8 to 15.4)

- $\mathrm{P}($ versus baseline $)=$ non-significant

\section{- Hemoglobin A1C}

- Proportion of children with hemoglobin $\mathrm{A} 1 \mathrm{C}<7.5 \%$ before and after the 24 -month follow-up period

- Baseline ( $N=138): 66.7 \%$

- After 6 months of FGM ( $N=137): 67.9 \%$

- $\mathrm{P}($ versus baseline $)=$ non-significant

- After 12 months of FGM ( $N=134): 54.5 \%$

- $P($ versus baseline $)=0.006$

- After 24 months of FGM ( $N=122): 59.0 \%$

- $P($ versus baseline $)=0.019$

- Proportion of children with hemoglobin $\mathrm{A} 1 \mathrm{C}<7.0 \%$ before and after the 24 -month follow-up period

- Baseline ( $N=138): 47.8 \%$

- After 6 months of FGM ( $N=137)$ : NR

- $\mathrm{P}($ versus baseline $)=\mathrm{NR}$ 
- After 12 months of FGM ( $N=134): 27.6 \%$

- $\mathrm{P}$ (versus baseline $)<0.0001$

- After 24 months of FGM ( $N=122): 31.1 \%$

- $P($ versus baseline $)=0.001$

- Mean hemoglobin A1C throughout the 24-month follow-up period

- Baseline ( $\mathrm{N}=138): 7.16 \%(95 \% \mathrm{Cl}, 7.0 \%$ to $7.3 \%)$

- After 6 months of FGM ( $\mathrm{N}=137): 7.26 \%$ (95\% Cl was presented in a figure; exact value could not be ascertained)

- $\mathrm{P}($ versus baseline $)=$ non-significant

- After 12 months of FGM ( $\mathrm{N}=134)$ : 7.62\% (95\% Cl, 7.4\% to $7.8 \%)$

- $\mathrm{P}$ (versus baseline $)<0.0001$

- After 24 months of FGM (N = 122): 7.56\% (95\% Cl, 7.4\% to $7.8 \%)$

- $P($ versus baseline $)<0.0001$

\section{- Total daily insulin dose}

- Mean total daily dose of insulin before and after the 24-month follow-up period (units $/ \mathrm{kg}$ )

- Baseline ( $N=138): 0.912$ ( $95 \% \mathrm{Cl}, 0.855$ to 0.970$)$ units $/ \mathrm{kg}$

- After 6 months of FGM ( $=137): 0.886$ ( $95 \% \mathrm{Cl}, 0.833$ to 0.939$)$ units $/ \mathrm{kg}$

- $\mathrm{P}($ versus baseline $)=$ non-significant

- After 12 months of FGM (N = 133): 0.860 ( $95 \%$ Cl, 0.815 to 0.904$)$ units/kg

- $P$ (versus baseline $)<0.01$

- After 24 months of FGM ( $N=122): 0.886$ ( $95 \% ~ C l, ~ 0.842$ to 0.930$)$ units $/ \mathrm{kg}$

- $\mathrm{P}($ versus baseline $)=$ non-significant

- Mean total daily dose of insulin before and after the 24-month follow-up period (units)

- Baseline ( $\mathrm{N}=138): 48.3$ ( $95 \% \mathrm{Cl}, 43.7$ to 52.9$)$ units

- After 6 months of FGM ( $N=137): 48.9(95 \% \mathrm{Cl}, 44.5$ to 53.2$)$ units

- $\mathrm{P}($ versus baseline $)=$ non-significant

- After 12 months of FGM ( $N=133): 49.1$ (95\% Cl, 45.2 to 53.0) units

- $\mathrm{P}($ versus baseline $)=$ non-significant

- After 24 months of FGM ( $N=122): 53.2$ (95\% Cl, 49.5 to 56.9) units

- $\mathrm{P}($ versus baseline $)<0.01$

- BMI

- Mean BMl of participants increased by $1.8 \mathrm{~kg} / \mathrm{m}^{2}$ throughout the 24 -month study period $(P<0.0001)$

- Mean BMI adjusted for age increased by 0.13 SDS ( $95 \% \mathrm{Cl}, 0.02$ to $0.24 ; \mathrm{P}=0.026)$

\section{- Adverse events}

- Proportion of participants who experienced hospitalizations due to hypoglycemia and/or ketoacidosis in the previous 12 months before and after the 24-month follow-up period

- Baseline ( $N$ = 138): 6.5\%

- After 12 months of FGM ( $=134): 2.2 \%$

- $\mathrm{P}($ versus baseline $)=$ non-significant 
- After 24 months of FGM ( $N=122): 6.6 \%$

- $\mathrm{P}($ versus baseline $)=$ non-significant

- Days of hospitalizations due to hypoglycemia and/or ketoacidosis in the previous 12 months per 100 patient years before and after the 24-month follow-up period

- Baseline ( $N=138): 18.8$ days per 100 patient years

- After 12 months of FGM ( $N=134): 7.1$ days per 100 patient years

- $\mathrm{P}$ (versus baseline $)<0.05$

- After 24 months of FGM ( $N=122): 26.4$ days per 100 patient years

- $\mathrm{P}($ versus baseline $)=$ non-significant

- Proportion of participants who experienced hospitalizations due to hypoglycemia in the previous 12 months before and after the 24-month follow-up period

- Baseline ( $N=138): 5.1 \%$

- After 12 months of FGM ( $N=134): 1.5 \%$

- $\mathrm{P}($ versus baseline $)=$ non-significant

- After 24 months of FGM ( $N=122): 0.8 \%$

- $\mathrm{P}($ versus baseline $)=$ non-significant

- Days of hospitalizations due to hypoglycemia in the previous 12 months per 100 patient years before and after the 24-month follow-up period

- Baseline ( $N=138): 2.9$ days per 100 patient years

- After 12 months of FGM ( $N=134): 0.4$ days per 100 patient years

- $\mathrm{P}$ (versus baseline $)<0.05$

- After 24 months of FGM ( $N=122): 5.7$ days per 100 patient years

- $\mathrm{P}($ versus baseline $)=$ non-significant

- Proportion of participants who experienced hospitalizations due to ketoacidosis in the previous 12 months before and after the 24-month follow-up period

- Baseline ( $N=138): 1.4 \%$

- After 12 months of FGM ( $N=134): 0.7 \%$

- $\mathrm{P}($ versus baseline $)=$ non-significant

- After 24 months of FGM ( $N=122): 5.7 \%$

- $\mathrm{P}($ versus baseline $)=$ non-significant

- Days of hospitalizations due to ketoacidosis in the previous 12 months per 100 patient years before and after the 24-month follow-up period

- Baseline ( $N=138): 15.9$ days per 100 patient years

- After 12 months of FGM ( $N=134): 6.7$ days per 100 patient years

- $\mathrm{P}($ versus baseline $)=$ non-significant

- After 24 months of FGM ( $N=122): 20.7$ days per 100 patient years

- $\mathrm{P}($ versus baseline $)=$ non-significant

o Proportion of participants who required help from a third party due to hypoglycemia in the previous 6 months before and after the 24-month follow-up period

- Baseline ( $N=106): 13.8 \%$

- After 6 months of FGM ( $N=94): 9.5 \%$ 
- $\mathrm{P}($ versus baseline $)=$ non-significant

- After 12 months of FGM ( $\mathrm{N}=86): 9.0 \%$

- $\mathrm{P}($ versus baseline $)=$ non-significant

- After 24 months of FGM ( $N=79): 13.1 \%$

- $\mathrm{P}($ versus baseline $)=$ non-significant

- Number of hypoglycemic events that required help from a third party in the previous 12 months per 100 patient years before and after the 24-month follow-up period

- Baseline ( $N=106): 65.2$ events per 100 patient years

- After 12 months of FGM ( $N=86): 37.3$ events per 100 patient years

- $\mathrm{P}($ versus baseline $)=$ non-significant

- After 24 months of FGM ( $\mathrm{N}=79)$ : 59.0 events per 100 patient years

- $\mathrm{P}($ versus baseline $)=$ non-significant

- Proportion of participants who experienced hypoglycemic comas in the previous 6 months before and after the 24-month follow-up period

- Baseline ( $N=111): 2.2 \%$

- After 6 months of FGM ( $=98): 0 \%$

- $\mathrm{P}($ versus baseline $)=$ non-significant

- After 12 months of FGM ( $N=91): 0.7 \%$

- $\mathrm{P}($ versus baseline $)=$ non-significant

- After 24 months of FGM ( $N=80): 0.8 \%$

- $\mathrm{P}($ versus baseline $)=$ non-significant

- Number of hypoglycemic comas in the previous 12 months per 100 patient years before and after the 24-month follow-up period

- Baseline ( $N=111)$ : 5.8 events/100 patient years

- After 12 months of FGM ( $N=91): 0.7$ events per 100 patient years

- $\mathrm{P}($ versus baseline $)=$ non-significant

- After 24 months of FGM ( $N=80): 1.6$ events per 100 patient years

- $\mathrm{P}($ versus baseline $)=$ non-significant

- Proportion of participants who experienced school absenteeism in the previous 6 months before and after the 24-month follow-up period

- Baseline ( $N=108): 13.8 \%$

- After 6 months of FGM ( $N=97): 9.5 \%$

- $\mathrm{P}($ versus baseline $)=$ non-significant

- After 12 months of FGM ( $N=90): 6.7 \%$

- $\mathrm{P}($ versus baseline $)=$ non-significant

- After 24 months of FGM ( $N=75): 4.8 \%$

- $\mathrm{P}($ versus baseline $)=$ non-significant

- Days of school absenteeism by participants in the previous 12 months per 100 patient years before and after the 24-month follow-up period

- Baseline ( $N=108)$ : 227.5 days per 100 patient years

- After 12 months of FGM ( $N=90): 65.2$ days per 100 patient years 
- $\mathrm{P}($ versus baseline $)=$ non-significant

- After 24 months of FGM ( $N=75): 13.1$ days per 100 patient years

- $P($ versus baseline $)=0.016$

- Proportion of parents of participants who experienced work absenteeism in the previous 6 months before and after the 24-month follow-up period

- Baseline ( $N=109): 19.6 \%$

- After 6 months of FGM ( $N=97): 18.2 \%$

- $\mathrm{P}($ versus baseline $)=$ non-significant

- After 12 months of FGM ( $N=89): 11.2 \%$

- $\mathrm{P}($ versus baseline $)=$ non-significant

- After 24 months of FGM ( $N=77): 8.2 \%$

- $\mathrm{P}($ versus baseline $)=$ non-significant

- Days of work absenteeism by parents of participants in the previous 12 months per 100 patient years before and after the 24-month follow-up period

- Baseline ( $N=109): 149.3$ days/100 patient years

- After 12 months of FGM ( $N=89): 87.3$ days per 100 patient years

- $\mathrm{P}($ versus baseline $)=$ non-significant

- After 24 months of FGM ( $N=77): 18.0$ days per 100 patient years

- $\mathrm{P}($ versus baseline $)=0.011$

\section{Authors' Conclusion}

"This study shows that [FGM] in a real-world pediatric population increases self-reported treatment satisfaction, without changing overall diabetes-related quality of life, and is well accepted by the children and their parents. With the use of [FGM], fewer days off school for the children with type 1 diabetes and fewer days off work for their parents could be achieved. However, there was no impact on acute hypoglycemia complications and diabetes-related hospitalizations. On the other hand, metabolic control worsened with an increase in hemoglobin A1C and BMI for the total population (p. 1470)."25

\section{Lim et al. (2020) ${ }^{26}$}

\section{Main Study Findings}

Single-centre, single-arm, prospective cohort study that evaluated the clinical effectiveness of FGM in adolescents with type 1 diabetes $(N=30)$. Prior to switching to FGM, participants were assumed to have been monitoring their glucose levels using SMBG.

Summary of relevant findings:

\section{- Self-efficacy}

- Mean CIDS total scores before and after the 4-week follow-up period

- Baseline ( $N=22): 78.14(S D=12.91)$

- After 4 weeks of FGM ( $N=22): 82.23(S D=12.79)$

- Overall change in score: $4.09(\mathrm{SD}=9.47)$

- $\mathrm{P}=0.05$

- Mean CIDS scores (questions 1 to 10) before and after the 4-week follow-up period

- Baseline ( $N=22): 39.68$ (SD = 6.38) 
- After 4 weeks of FGM $(\mathrm{N}=22): 42.68(S D=6.19)$

- Overall change in score: $3.00(S D=5.07)$

- $\mathrm{P}=0.01$

- Mean CIDS scores (questions 11 to 20) before and after the 4-week follow-up period

- Baseline ( $N=22): 38.45$ (SD = 7.15)

- After 4 weeks of FGM (N = 22): 39.55 (SD = 6.95)

- Overall change in score: $1.09(S D=5.38)$

- $\mathrm{P}=0.35$

\section{- Glucose levels}

- Mean glucose levels throughout the previous 14 days before and after switching to FGM

- Baseline ( $N=22): 12.06(S D=2.31) \mathrm{mmol} / \mathrm{L}$

- After 2 weeks of FGM ( $\mathrm{N}=22): 11.98(\mathrm{SD}=3.55) \mathrm{mmol} / \mathrm{L}$

- Overall change (versus baseline): $0.08(\mathrm{SD}=3.22) \mathrm{mmol} / \mathrm{L}$

- $P$ (versus baseline $)=1.00$

- After 4 weeks of FGM ( $\mathrm{N}=22): 11.39$ (SD = 3.05) $\mathrm{mmol} / \mathrm{L}$

- Overall change in score (versus baseline): $0.67(\mathrm{SD}=3.07) \mathrm{mmol} / \mathrm{L}$

- $P$ (versus baseline $)=0.94$

\section{- Adverse events}

- Mean number of hypoglycemic events (<3.0 mmol/L [ $<70 \mathrm{mg} / \mathrm{dL}])$ throughout the previous 14 days before and after switching to FGM

- Baseline ( $N=22): 2.45(S D=2.01)$

- After 2 weeks of FGM ( $=22): 9.05(\mathrm{SD}=6.57)$

- Overall change (versus baseline): $6.59(S D=6.83)$

- $P($ versus baseline $)=0.001$

- After 4 weeks of FGM ( $=22): 8.27$ (SD = 5.48)

- Overall change (versus baseline): 5.81 ( $S D=5.39)$

- $P($ versus baseline $)<0.001$

\section{Authors' Conclusion}

"This 4-week pilot program illustrated the feasibility of FGM as a useful home-based system that does not require intensive training. Although participants' time in range improved, hypoglycemic events did not decrease. The cost-effectiveness of this system remains unclear for this population of patients. Careful patient selection and further research could determine the best selection criteria for adolescents who might benefit from FGM use. Diabetes technology expenses are generally paid out of pocket by patients in Singapore. In this population of adolescents with poorly controlled diabetes, a more advanced closed-loop automated pump and sensor system might better facilitate improved time in range and reduced hypoglycemia (p. 157-158)."${ }^{\prime 26}$

\section{Al Hakey et al. (2019) $)^{27}$ Main Study Findings}

Single-centre, single-arm, prospective cohort study that investigated mental well-being and patient satisfaction in a pediatric and young adult population with type 1 diabetes ( $\mathrm{N}$ 
= 33) who used FGM. Before switching to FGM, participants were monitoring their glucose levels using SMBG.

Summary of relevant findings:

\section{- Patient satisfaction}

- Mean DTSQ satisfaction scores before and after the 12-week follow-up period

- Baseline ( $N=33): 14.4(S D=6.0)$

- After 12 weeks of FGM (N = 33): $31.7(\mathrm{SD}=1.9)$

- Change from baseline: $17.3(S D=6.7)$

- $P<0.001$

\section{- Quality of life}

- Mean WHO-5 scores before and after the 12-week follow-up period

- Baseline ( $N=33): 11.3(S D=4.2)$

- After 12 weeks of FGM (N = 33): $23.4(S D=1.6)$

- Change from baseline: $12.1(\mathrm{SD}=4.0)$

- $\mathrm{P}<0.001$

\section{Authors' Conclusion}

"In conclusion, the use of the FreeStyle Libre along with insulin pump or MDII treatment in children and young adults with type 1 diabetes led to significantly greater satisfaction and a stronger sense of well-being compared with the baseline conventional finger-pricking method (p.1246)."27

\section{Deeb et al. (2019) $)^{28}$ \\ Main Study Findings}

Single-centre, single-arm, prospective cohort study that assessed the impact of FGM on detecting hypoglycemia and on adherence to glucose monitoring in children and adolescents with type 1 diabetes $(N=75)$. Before switching to FGM, participants were monitoring their glucose levels using SMBG.

Summary of relevant findings:

\section{- Frequency of glucose monitoring}

- Median of the average daily number of glucose checks before and after switching to FGM

- Baseline ( $N=72): 2.87$ (IQR, 1 to 6$)$

- After 2 to 4 weeks of FGM ( $N=72): 11$ (IQR, 3 to 44)

- $\mathrm{P}<0.001$

\section{- Frequency of detecting hypoglycemic events}

- Median number of diurnal hypoglycemia events detected using glucose monitoring before and after switching to FGM

- Baseline ( $N=72): 0.0$

- After 2 to 4 weeks of FGM ( $N=72): 4.0$ 
- $\mathrm{P}<0.01$

- Median number of nocturnal hypoglycemia events detected using glucose monitoring before and after switching to FGM

- Baseline ( $N=72): 0.0$

- After 2 to 4 weeks of FGM ( $N=72): 3.0$

- $\mathrm{P}<0.01$

\section{Authors' Conclusion}

"Our study shows that use of flash glucose monitoring for ambulatory glucose monitoring system enhances patients' compliance of glucose monitoring. It improves detection of hypoglycemia and its duration. Lack of calibration requirement and the longer wear period of the sensor help improving clinical outcome of diabetes in children and young people (p. 5)."28

\section{Pintus et al. (2019) ${ }^{29}$ Main Study Findings}

Single-centre, single-arm, prospective cohort study that assessed the effectiveness of FGM in children with type 1 diabetes $(N=52)$ with respect to metabolic outcomes and quality of life. Prior to switching to FGM, participants were assumed to have been monitoring their glucose levels using SMBG.

Summary of relevant findings:

\section{- Hemoglobin A1C}

- Mean hemoglobin A1C 12 months before and 3 months after switching to FGM

- 12 months before switching ( $\mathrm{N}=\mathrm{NR}$ ): $62 \mathrm{mmol} / \mathrm{mol}$

- 3 months after switching ( $\mathrm{N}=\mathrm{NR}): 59.5 \mathrm{mmol} / \mathrm{mol}$

- Difference: $2.5(95 \% \mathrm{Cl}, 0.1$ to 4.8$) \mathrm{mmol} / \mathrm{mol}$

- $\mathrm{P}=0.040$

- Mean hemoglobin A1C 6 months before and 3 months after switching to FGM

- 6 months before switching $(\mathrm{N}=\mathrm{NR}): 61.9 \mathrm{mmol} / \mathrm{mol}$

- 3 months after switching ( $N=N R): 59.5 \mathrm{mmol} / \mathrm{mol}$

- Difference: $2.4(95 \% \mathrm{Cl}, 0.1$ to 4.4$) \mathrm{mmol} / \mathrm{mol}$

- $P=0.040$

- Mean hemoglobin A1C 3 months before and 3 months after switching to FGM

- 3 months before switching ( $\mathrm{N}=\mathrm{NR}): 65.2 \mathrm{mmol} / \mathrm{mol}$

- 3 months after switching ( $N=N R): 59.5 \mathrm{mmol} / \mathrm{mol}$

- Difference: 5.7 (95\% Cl, 1.4 to 11$) \mathrm{mmol} / \mathrm{mol}$

- $\mathrm{P}=0.012$

- Mean hemoglobin A1C 3 months before and 6 months after switching to FGM

- 3 months before switching ( $\mathrm{N}=\mathrm{NR}): 66.8 \mathrm{mmol} / \mathrm{mol}$

- 6 months after switching $(\mathrm{N}=36): 62.6 \mathrm{mmol} / \mathrm{mol}$

- Difference: 4.2 (95\% Cl, - 1.6 to 9.9$) \mathrm{mmol} / \mathrm{mol}$

- $P=0.15$ 
- Mean hemoglobin A1C 3 months before and 12 months after switching to FGM

- 3 months before switching $(\mathrm{N}=\mathrm{NR}): 65.9 \mathrm{mmol} / \mathrm{mol}$

- 12 months after switching $(\mathrm{N}=30): 63.7 \mathrm{mmol} / \mathrm{mol}$

- Difference: $2.2(95 \% \mathrm{Cl},-4.3$ to 8.6$) \mathrm{mmol} / \mathrm{mol}$

- $P=0.50$

\section{- Quality of life}

- Mean PedsQL total scores before and 3 months after switching to FGM

- Baseline ( $N=N R): 75.6$

- 3 months after switching ( $N=N R): 82.5$

- Difference: - $6.9(95 \% \mathrm{Cl},-1.6$ to -12.1$)$

- $\mathrm{P}=0.014$

- Mean PedsQL symptoms scores before and 3 months after switching to FGM

- Baseline ( $N$ = NR): 57.8

- 3 months after switching ( $N=N R): 66.5$

- Difference: - 8.6 (95\% Cl, 1.7 to - 15.6)

- $\mathrm{P}=0.018$

- Mean PedsQL treatment barrier scores before and 3 months after switching to FGM

- Baseline ( $N$ = NR): 63.3

- 3 months after switching ( $N=N R): 73.9$

- Difference: $-10.6(95 \% \mathrm{Cl},-2.4$ to -10.9$)$

- $\mathrm{P}=0.035$

\section{Authors' Conclusion}

"Our study supports the use of FGM system in children with type 1 diabetes mellitus. The FGM technology associated with appropriate education at the initiation of the technology and regular support by healthcare professionals improves patient quality of life measures in children with type 1 diabetes mellitus. Further long-term randomised control trials studies are necessary to look at the glycaemic control in the long-term (p. 2929)."29 


\section{Appendix 5: References of Potential Interest}

\section{Previous CADTH Reports}

1. Boucher M, Pant S, Jinah A, Tsoi B, Walter M. Flash glucose monitoring system Freestyle Libre to monitor glycemia in patients with diabetes. (CADTH technology review; no. 33). Ottawa (ON): CADTH; 2020: https://cadth.ca/ sites/default/files/hta-he/ho0009-tech-review-flash-glucose-monitoring-system-freestyle-libre.pdf. Accessed 2021 Mar 31.

\section{Review Articles}

2. Bailey CJ, Gavin JR, 3rd. Flash continuous glucose monitoring: a summary review of recent real-world evidence. Clin Diabetes. 2021 Jan;39(1):64-71. PubMed

3. Lin R, Brown F, James S, Jones J, Ekinci E. Continuous glucose monitoring: a review of the evidence in type 1 and 2 diabetes mellitus. Diabet Med. 2021 Jan 26:e14528. PubMed

4. Cappon G, Vettoretti M, Sparacino G, Facchinetti A. Continuous glucose monitoring sensors for diabetes management: a review of technologies and applications. Diabetes Metab J. 2019 08;43(4):383-397. PubMed

5. Stueve M, Schnell O. Health Technology Assessments for flash glucose monitoring and how to use them in everyday clinical practice. J Diabetes Sci Technol. 2019 05;13(3):584-591. PubMed

6. Leelarathna L, Wilmot EG. Flash forward: a review of flash glucose monitoring. Diabet Med. 2018 Apr;35(4):472-482. PubMed

7. Mancini G, Berioli MG, Santi E, et al. Flash glucose monitoring: a review of the literature with a special focus on type 1 diabetes. Nutrients. 2018 Jul 29;10(8):29. PubMed

\section{Randomized Controlled Trials - Protocols}

8. Boucher SE, Gray AR, de Bock M, et al. Effect of 6 months' flash glucose monitoring in adolescents and young adults with type 1 diabetes and suboptimal glycaemic control: managing diabetes in a 'flash' randomised controlled trial protocol. BMC Endocr Disord. 2019 May 20;19(1):50. PubMed 